\title{
An Inter-laboratory Trial of the Unified BARGE Bioaccessibility Method for Arsenic, Cadmium and Lead in Soil
}

\author{
Joanna Wragg ${ }^{1}$, Mark Cave ${ }^{1}$, Nick Basta ${ }^{2}$, Esther Brandon ${ }^{3}$, Stan Casteel $^{4}$, \\ Sebastien Denys ${ }^{5}$, Christian Gron ${ }^{6}$, Agnes Oomen ${ }^{3}$, Kenneth Reimer ${ }^{7}$, Karine \\ Tack $^{5}$ and Tom Van de Wiele .
}

${ }^{1}$ British Geological Survey, Nottingham, United Kingdom

${ }^{2}$ School of Environment and Natural Resources, The Ohio State University, Columbus, Ohio, 43210-1085, USA

${ }^{3}$ National Institute for Public Health and the Environment, Bilthoven, The Netherlands

${ }^{4}$ College of Veterinary Medicine, University of Missouri, 65205, USA

${ }^{5}$ INERIS, Parc Technologique Alata, Verneuil-en-Halatte, France

${ }^{6}$ DHI Water Environment Health, Horsholm, Denmark

${ }^{7}$ Environmental Sciences Group, Royal Military College of Canada, Kingston, Ontario, Canada

${ }^{8}$ Laboratory of Microbial Ecology and Technology, University of Ghent, Ghent, Belgium

\section{ABSTRACT}

The Bioaccessibility Research Group of Europe (BARGE) has carried out an interlaboratory trial of a proposed harmonised in vitro physiologically based ingestion bioaccessibility procedure for soils, called the Unified BARGE Method (UBM). The UBM includes an initial saliva phase and simulated stomach and intestine compartments. The trial involved the participation of seven laboratories (five European and two North American) providing bioaccessibility data for As (11 samples), Cd (9 samples) and $\mathrm{Pb}$ (13 samples) using soils with in vivo relative bioavailability data measured using a swine model. The results of the study were compared with benchmark criteria for assessing the suitability of the UBM to provide data for human health risk assessments. Mine waste and slag soils containing high concentrations of As caused problems of poor repeatability and reproducibility which were alleviated when the samples were run at lower soil to solution ratios. The study showed that the UBM met the benchmark criteria for both the stomach and stomach \& intestine phase for As. For Cd, three out of four criteria were met for the stomach phase but only one for the stomach \& intestine phase. For Pb two, out of four criteria were met for the stomach phase and none for the stomach $\&$ intestine phase. However, the study recommends tighter control of $\mathrm{pH}$ in the stomach phase extraction to improve between-laboratory variability, more reproducible in vivo validation data and that a follow up inter-laboratory trial should be carried out.

Keywords: bioaccessibility; bioavailability; inter-laboratory trial; soil; risk assessment; in vivo; in vitro

\section{Introduction}

The Bioaccessibility Research Group of Europe (BARGE, http://www.bgs.ac.uk/barge/home.html) is a European network bringing together 
international institutes and research groups to study human bioaccessibility of priority contaminants in soils via the gastrointestinal (GI) tract. The key contaminants included in this work are arsenic $(\mathrm{As})$, lead $(\mathrm{Pb})$ and cadmium $(\mathrm{Cd})$ as they are potentially harmful to human health (ATSDR, 2007b; ATSDR, 2007a; ATSDR, 2008) and the most common elements undergoing bioaccessibility research (Smith et al., ; Ruby et al., 1993; Ruby et al., 1996; Albores et al., 2000; Oomen et al., 2002; Marschner et al., 2006; Chan et al., 2007; Datta et al., 2007; Drexler and Brattin, 2007; Finzgar et al., 2007; Hansen et al., 2007; Juhasz et al., 2007a, 2007b; Ljung et al., 2007; Sarkar et al., 2007; Subacz et al., 2007; Turner and Ip, 2007; Van de Wiele et al., 2007; Beak et al., 2008; Moseley et al., 2008; Girouard and Zagury, 2009; Morman et al., 2009; Nagar et al., 2009; Poggio et al., 2009; Smith et al., 2009; Zhang et al., 2009; Demetriades et al., 2010; Juhasz et al.2010). These contaminants are associated with a legacy of industrial activities (Gasser et al., 1996; Razo et al., 2006; Rieuwerts et al., 2006; Basta et al., 2007; Laird et al., 2007; Morrison and Gulson, 2007; Bosso and Enzweiler, 2008; Bosso et al., 2008; Romero et al., 2008; Caboche et al.,2010; Meunier et al.,2010; Roussel et al., 2010) and natural background geology (Fendorf et al., 2004; Koch et al., 2005; Nathanail et al., 2005; Palumbo-Roe et al., 2005; Wragg, 2005; Cave et al., 2007; Juhasz et al., 2007b; Wragg et al., 2007), which are of concern to a number of the countries participating in BARGE.

The accurate determination of bioaccessibility has the potential to make a significant impact on current risk assessment practice. BARGE has been involved in comparing and evaluating the physico-chemical processes within the many models and systems that have been developed over the years to measure bioaccessibility and contaminant exposure e.g. (Oomen et al., 2002; Basta et al., 2007; Cave et al., 2007; Chan et al., 2007; Gal et al., 2007; Gron et al., 2007; Ljung et al., 2007; Nathanail and Smith, 2007; Palumbo-Roe and Klinck, 2007; Subacz et al., 2007; Van de Wiele et al., 2007; Wragg et al., 2007; Wragg and Klinck, 2007). A priority objective is to provide robust and defensible data on bioaccessibility that can be used in human health risk assessments and policy making.

The concepts of bioaccessibility and oral bioavailability are fundamentally important for quantifying the risks that are associated with oral exposure to environmental contaminants. Bioaccessibility refers to the fraction of a contaminant that is released from soil into solution by digestive juices. It represents the maximum amount of contaminant that is available for intestinal absorption. In general, only a fraction of these bioaccessible contaminants can be absorbed by the intestinal epithelium. Inorganic contaminants are 
subsequently transported to the liver via the portal vein for biotransformation. The fraction of parent compound that reaches the systemic circulation is referred to as the bioavailable fraction. Given the fact that bioaccessibility is one of the principal factors limiting the bioavailable fraction, it is an important parameter to measure for risk assessment purposes.

Bioavailability data from actual human soil feeding tests is scarce (Maddaloni et al., 1998; Stanek et al.,2010) and although in vivo animal studies are have been carried out, these are, in general costly, time consuming, have ethical constraints and there is usually only a limited amount of soil available (Freeman et al., 1992; Freeman et al., 1993; Ruby et al., 1993; Freeman et al., 1995; Golub et al., 1999; Rodriguez et al., 1999; Ellickson et al., 2001; Schroder et al., 2003; Schroder et al., 2004; Marschner et al., 2006; Makris et al., 2008; Bannon et al., 2009; Nagar et al., 2009) and Juhasz et al (2007a, 2008, 2009a, $2009 b$ ). An alternative is the application of in vitro models that simulate the GI tract. These screening methods can be used to measure the bioaccessible contaminant fraction, as bioaccessibility is an important parameter prior to bioavailability. A number of in vitro bioaccessibility tests for mimicking human ingestion have been reported in the literature and have been comprehensively reviewed (Wragg and Cave, 2003; Dean and Ma, 2007). Of these, there are four batch extraction methods which are most commonly used : the physiologically based extraction test (PBET) originally developed by Ruby (1996); the in vitro gastrointestinal method (IVG) (Rodriguez et al., 1999); the Dutch National Institute for Public Health and the Environment method (RIVM) (Versantvoort et al., 2004) which is mainly used in Europe; and the relative bioaccessibility leaching procedure (RBALP) which was developed specifically for Pb in soils (Drexler and Brattin, 2007). The PBET, IVG, and RIVM methods use extraction media that closely mimic the chemical environment of the human gastrointestinal system i.e. they are physiologically based, whereas the RBALP uses physiologically relevant $\mathrm{pH}$ of the stomach but uses a glycine buffer as the extraction medium.

As a result of research carried out by BARGE and other research groups it was clear that the different bioaccessibility tests showed similar trends when used on the same soil samples, but the different operating conditions for each test produced widely ranging bioaccessibility values between the methods (Oomen et al., 2002; Saikat et al., 2007; Van de Wiele et al., 2007; Juhasz et al., 2009a; 2009b). For example, in a study of five 
different methods on three test soils (Oomen et al., 2002)a wide range of bioaccessibility values were found: for As 6-95\%, 1-19\%, and 10-59\%; for $\mathrm{Cd} 7-92 \%, 5-92 \%$, and 6$99 \%$; and for $\mathrm{Pb} 4-91 \%, 1-56 \%$, and 3-90\%. This made comparison of data difficult to carry out in a subjective manner causing regulators and risk assessors some concern (Environment Agency, 2005b; Environment Agency, 2005a; Environment Agency, 2007; Richardson, 2008; Scheckel et al., 2009; Latawiec et al., 2010). To overcome this problem, BARGE undertook a joint decision to progress the development of a harmonised in vitro bioaccessibility method.

The main criteria for the test were:

i) It should be physiologically based, mimicking the human GI physico-chemical environment in the stomach and small intestine. This should not only help to obtain good agreement with in vivo data but would also enhance public understanding of the test;

ii) It should represent a conservative case;

iii) There should be one set of conditions for all potentially harmful elements (PHE) being studied;

iv) It must be demonstrated that the test is a good analogue of in vivo conditions; and

v) The test must be able to produce repeatable and reproducible results within and between testing laboratories.

The chosen method was that previously published by researchers at the Dutch Institute of Public Health, the RIVM (Oomen, 2000; Oomen et al., 2002), as this was considered to be the most suitable static or batch method available, and therefore more likely to be adopted by testing laboratories. The RIVM methodology has also gained acceptance by regulators in both the Netherlands and Denmark. Modifications were made to the RIVM methodology to ensure adequate conservatism, that the in vitro test was robust and applicable to the different soil types found in a range of different countries. 


\section{Method performance and benchmarks}

The evaluation of the UBM was undertaken by means of an international inter-laboratory exercise. For the method to be 'fit for purpose' the bioaccessibility would need to pass quantitative tests on how well the test could be validated by an in vivo result and how reliably the test could be carried out (repeatability and reproducibility). A validation study of a simple one compartment bioaccessibility test (not physiologically based) for $\mathrm{Pb}$ has recently been carried out (Drexler and Brattin, 2007) and shows some very impressive statistical performance figures for both validation and reliability.

Although there is not much literature on acceptability criteria for in vitro/in vivo validation of bioaccessibility tests in soil, there is an equivalent in vitro/in vivo correlation test (IVIVC) used widely in the pharmaceutical industry. The IVIVC test is a tool designed to correlate in vitro and in vivo drug release (Emami, 2006). The bioavailability of the administered drug, measured by the fraction of the drug absorbed into the human body (equivalent to the animal testing data for metal uptake from soil) is correlated to the in vitro bioaccessibility measured by a dissolution test (equivalent to the UBM bioaccessibility test for soil). The US Federal Drug Administration has set out guidelines for the acceptability of results (1997) which include:

i) A linear relationship with slope of unity, if possible, is preferred, to show that the in vitro dissolution is representative in vivo absorption;

ii) The relative standard deviation (RSD) for the in vitro measurement of a single sample should be less than 10\% (repeatability);

iii) The prediction error of the in vivo absorption from the in vitro dissolution test should not exceed $15 \%$ for each formulation (sample).

This provides a basis for setting up performance criteria for the soil bioaccessibility validation. Pharmaceutical formulations are, however, far more homogeneous and less complex than soil samples and therefore these criteria may be too stringent for soil testing. It is necessary to go to the literature to look at the repeatability of inter-laboratory trials on soil testing. Drexler's soil bioaccessibility inter-laboratory trial (2007) reported a repeatability of $4 \%$ and reproducibility of $6 \%$ (measured as the percent RSD). There are not many other inter-laboratory studies for bioaccessibility testing available; however, there are instances of laboratory trials on soils where PHEs are extracted using different 
reagents to determine their solid phase distribution and speciation, which is similar to the UBM bioaccessibility test. In the inter-laboratory trial for the European Community Bureau of Reference (BCR) sequential extraction test on a lake sediment (Quevauviller, 2002) the between-laboratory repeatability for Cd was 15,13 and $75 \%$ RSD for three

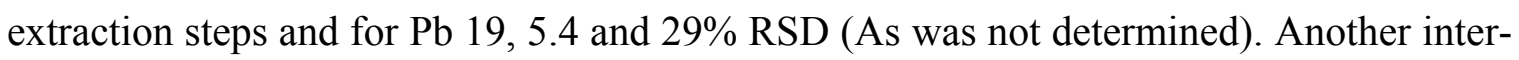
laboratory trial on soils (Nagourney et al., 2008) used a standard extraction test to determine the $\mathrm{Cr}^{\mathrm{VI}}$ content of a reference soil giving an inter-laboratory RSD of $\sim 20 \%$. This clearly shows that between-laboratory repeatability in soil extraction studies of PHEs can be highly variable.

Using the combined information from IVIVC and from soil extraction literature the following soil bioaccessibility testing validation criteria (benchmark criteria) are proposed:

i) There should be a linear relationship between the relative bioaccessibility and the relative bioavailability where relative bioavailability/bioaccessibility refers to the bioavailable/bioaccessible fraction of the contaminant in the soil relative to the bioavailability/bioaccessibility of a soluble salt of the contaminant. A slope of unity, if possible, is preferred, to show that the in vitro bioaccessibility is representative of the bioavailability study; the linear relation should be demonstrated by a very strong correlation coefficient $\left(r>0.8\right.$ or $\left.r^{2}>0.6\right)$ and a slope $>0.8$ and $<1.2$

ii) The within-laboratory repeatability should be $\leq 10 \%$ RSD

iii) The between-laboratory reproducibility should be $\leq 20 \%$ RSD

\section{Materials and methods}

\subsection{Samples under investigation}

The materials under investigation included slag materials, soils, river sediments and house dusts containing in vivo data for $\mathrm{As}, \mathrm{Cd}$ and $\mathrm{Pb}$. A number of the donated soils had previously been studied in bioaccessibility investigations and the resulting data reported in the peer reviewed literature (Rodriguez et al., 1999; Rodriguez et al., 2003; Schroder et al., 2003; Schroder et al., 2004; Basta et al., 2007). Where information on the source of the material, contaminants and subsequent testing data was not readily available in the literature, it was provided by the donor of the individual samples. In addition to in vivo tested soils as a primary source of contaminated material, the evaluation of the UBM also included the two National Institute of Standards and Technology (NIST) standard 
reference materials (SRMs), 2710 and 2711, which have been studied by various workers in relation to their bioaccessible contaminant contents (Ellickson et al., 2001; Cave et al., 2003; Schroder et al., 2004). and a soil (BGS 102), containing naturally elevated As concentrations, prepared by the British Geological Survey (BGS) specifically for the purposes of bioaccessibility testing (Wragg, 2009). Table 1 summarises the materials studied in the inter-laboratory trial, including the material type, references to published information and the total and relative bioavailable data available.

\subsection{In vitro bioaccessibility method}

The in vitro UBM, was a physiological GI simulation based on the methodology utilized at the RIVM, previously described by Oomen et al (2002). The procedure was carried out according to the schematic in Figure 1 and has been described in full in other publications (Wragg et al., 2009; Roussel et al., 2010). The UBM was carried out at $37^{\circ} \mathrm{C}$ (body temperature), at a final soil:solution ratio of 1:100 $\left(\mathrm{g} \mathrm{ml}^{-1}\right)$ with end over end rotation at $30 \mathrm{rpm}$. The simulation consisted of three stages: the mouth, stomach and small intestinal cavities at a stomach $\mathrm{pH}$ of 1.2 and an intestinal $\mathrm{pH}$ of 6.3 under fasting conditions, which produced two individual extracts per test sample for analysis. The sample known as 'stomach' phase consisted of an extraction solution removed from the system after simulation of the mouth (utilizing simulated salival fluid) followed by the stomach (utilizing simulated stomach fluid) compartments. The sample known as 'stomach \& intestine' represented the extraction solution removed after simulation of the mouth, stomach and small intestine (utilizing simulated saliva, stomach, bile and duodenal fluids) phases of the system. The chemical constituents included in each phase were the same as those previously reported (Oomen et al., 2002), with the exception the duodenal fluid, which contained an increased concentration of sodium hydrogen carbonate $\left(5.607 \mathrm{~g} \mathrm{l}^{-1}\right.$ compared with $3.388 \mathrm{~g} \mathrm{l}^{-1}$ in the original methodology). The increased sodium hydrogen carbonate concentration was employed to compensate for the lower, but still physiologically acceptable, stomach $\mathrm{pH}$ used in the method (1.2 compared with 1.5 used by the RIVM method). The reason for reducing the $\mathrm{pH}$ to 1.2 was based on preliminary studies where calcareous soils were found to cause difficulties in maintaining a low $\mathrm{pH}$ in the stomach phase. Reducing the $\mathrm{pH}$ to a lower but still physiologically acceptable value of 1.2 helped to alleviate this practical difficulty. 
In summary, $9.0 \mathrm{ml}$ of salival fluid was added by pipette to $0.6 \mathrm{~g}$ of test material for both the 'stomach' and the 'stomach \& intestine' extractions; the extraction vessels were capped and shaken manually for $30 \mathrm{~s}$. To each test aliquot, $13.5 \mathrm{ml}$ of gastric fluid was added and the extraction vessels were capped and placed into an extractor and incubated using end-over-end rotation, at $37 \pm 2{ }^{\circ} \mathrm{C}$ for 1 hour. At the end of 1 hour both the 'stomach' and 'stomach \& intestine' extracts were removed from the incubator and the $\mathrm{pH}$ of the suspension measured. If the $\mathrm{pH}$ of the suspension was measured at $1.2-1.7$, the 'stomach' phase extract was deemed complete and the 'stomach \& intestine' extract was taken forward to carry out the intestinal digestion phase. If the $\mathrm{pH}$ tolerance was not met and there was sufficient solid material available, the UBM extraction was repeated and the $\mathrm{pH}$ was adjusted to between $1.2-1.7$ using up to $1.0 \mathrm{ml}$ of concentrated $\mathrm{HCl}$ $(37 \%$ or $12 \mathrm{~N})$. If the $\mathrm{pH}$ criterion was met, the 'stomach' phase extract was centrifuged at $3000 \mathrm{~g}$ for 5 minutes and a $1.0 \mathrm{ml}$ aliquot preserved by the accurate addition $9.0 \mathrm{ml}$ of $0.1 \mathrm{M} \mathrm{HNO}_{3}$. To continue the extraction and carry out the 'stomach \& intestine' phase, $27.0 \mathrm{ml}$ of duodenal fluid and $9.0 \mathrm{ml}$ of bile fluid were added by pipette, the samples recapped, manually shaken for $30 \mathrm{~s}$ and the $\mathrm{pH}$ checked to ensure that it was $6.3 \pm 0.5$. If the $\mathrm{pH}$ criterion was not met, the $\mathrm{pH}$ was adjusted by the dropwise addition of $37 \% \mathrm{HCl}$, $1 \mathrm{M}$ or $10 \mathrm{M} \mathrm{NaOH}$ as required and then replaced in the incubator at $37^{\circ} \mathrm{C}$ and rotated for a further 4 hours. At the end of the intestinal incubation period, the $\mathrm{pH}$ was recorded and the suspensions centrifuged for 5 minutes at $3000 \mathrm{~g}$. An aliquot of the supernatant was collected and preserved in the same manner as the 'stomach' phase extractions. Both extraction phases were stored at $1-8^{\circ} \mathrm{C}$. For both the 'stomach' and 'stomach \& intestine' phases of the UBM, all contributing laboratories made a record of any additional $\mathrm{HCl}$ or $\mathrm{NaOH}$ adjustments made to either phase. Because of the small amount of material available for the inter-laboratory trial, it was not possible for all contributing laboratories to carry out repeat extractions because of $\mathrm{pH}$ tolerance failures, and therefore some data was reported that was outside the scope of the required tolerances. Two laboratories also carried out the UBM extractions for the As soils at a lower soil to solution ratio of 1:1000 $\mathrm{g} \mathrm{ml}^{-1}$. Because the bioaccessible element content of BGS 102 was assumed to be relatively low compared with the in vivo validation soils, based on the total element concentration data available, the contributing laboratories provided an additional $10.0 \mathrm{ml}$ aliquot of unpreserved and therefore undiluted 'stomach' and 'stomach $\&$ intestine' extract for analysis. 
Prior to evaluation of the UBM, a detailed Standard Operating Procedure (SOP) was agreed by all BARGE laboratory participants (the BGS, DHI, INERIS, Ohio State University, RIVM, the Royal Military College of Canada (RMC) and the University of Ghent) (Wragg 2009). The lead laboratory (BGS) issued instructions to all participating laboratories, which included a list of materials to be investigated and the number of duplicate, blank and spike extractions expected. To ensure standardisation of the procedure and reduction in uncertainty estimates, all equipment and reagents were sourced by each laboratory from the same suppliers. Where a contributing laboratory was unable to obtain the required reagents, the lead laboratory satisfied the requirement by supplying said laboratory. Polypropylene tubes with screw top lids (101 x 16.5mm, with a capacity of $13 \mathrm{ml}$ ) were provided to each laboratory for sample storage and transportation and a simple digestion and analysis that was carried out by the lead laboratory. The lead laboratory carried out digestion of the extracts in order to re-solubilise any analytes sorbed to the surface of the tubes during transit and storage, and to ensure that all samples were of the same acidic matrix for analysis, regardless of minor operational differences applied in the individual laboratories. To each digestion tube $1.0 \mathrm{ml}$ of AristaR grade ${ }^{\circledR}$ concentrated $\mathrm{HNO}_{3}$ and $1.0 \mathrm{ml}$ of $70 \% \mathrm{v} / \mathrm{v} \mathrm{H}_{2} \mathrm{O}_{2}$ were added by auto-pipette and the tubes loosely capped and placed in a temperature controlled hot-block for 3 hours at 70 ${ }^{\circ} \mathrm{C}$. After cooling the samples were capped tightly and stored at $1-8{ }^{\circ} \mathrm{C}$ prior to analysis. Full details of the selection criteria for the sample tubes and the digestion procedure have been fully described by Wragg et al. (2009).

\subsection{Bioaccessibility extract analysis}

The bioaccessible $\mathrm{As}, \mathrm{Cd}$ and $\mathrm{Pb}$ content of each extract provided was determined directly by a Varian/Vista AX CCD simultaneous instrument with dedicated Varian SPS5 Auto-sampler and PC running the latest version of ICP Expert software supplied by the instrument manufacturer, according to the operating conditions previously described (Cave and Wragg, 2002; Wragg, 2005). Each sample was introduced with 1\% caesium chloride (as an ionisation buffer) via a peristaltic pump into a glass concentric slurry nebuliser connected to a cyclonic action spray chamber. Analysis was carried out on $\sim 2.5$ $\mathrm{ml}$ of the UBM digested 'stomach', 'stomach \& intestine' extraction solution. Arsenic, $\mathrm{Cd}$ and $\mathrm{Pb}$ were determined in the UBM extracts after calibration using a minimum of 5 mixed element standards in a $1 \% \mathrm{HNO}_{3}$ matrix. The 'inductively coupled plasma-optical emission spectrometer (ICP-OES) was calibrated to concentrations up to $100 \mathrm{mg} \mathrm{l}^{-1}$ for 
$\mathrm{As}$ and $\mathrm{Pb}$ and $10 \mathrm{mg}^{-1}$ for $\mathrm{Cd}$ and re-calibrated after not more than 125 unknown samples. Two quality control standards, at $\sim 10$ and $75 \%$ of the calibration range, were analysed after each calibration, after no more than ten unknown solutions during the run and at the end of each run to check for drift. As the bioaccessibility matrix had been diluted to a ratio of $1: 10\left(\mathrm{~g} \mathrm{ml}^{-1}\right)$ with $0.1 \mathrm{M} \mathrm{HNO}_{3}$ prior to shipping, and digested in mixed $\mathrm{HNO}_{3} / \mathrm{H}_{2} \mathrm{O}_{2}$ on arrival at the lead laboratory no further matching to the calibration

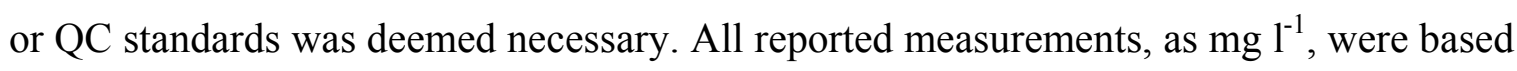
on the average of three 10 second replicate measurements. All element concentrations quoted have been converted into $\mathrm{mg} \mathrm{kg}^{-1}$ extracted from the solid. The analysis of unpreserved BGS 102 was carried out using a Thermo Elemental ExCell quadrupole ICPMS instrument in combination with a Cetac ASX-510 autosampler, according to the operating conditions previously described by Watts et al. (2008). The instrument was calibrated at the beginning of each analytical run using standards prepared from certified Claritas $\mathrm{PPT}^{\circledR}$ (Spex CertiPreP) multi-element solutions in the range 0 to $50 \mu \mathrm{g} \mathrm{l}^{-1}$. In addition, $10 \mu \mathrm{g}^{-1}$ mixed element standards were inserted at regular intervals throughout the analysis run and used to correct for any drift in instrument sensitivity. Indium and rhenium were added to all solutions via a T-piece connection and used as internal standards to correct for any matrix suppression. Multi-element QC standards, containing $\mathrm{As}, \mathrm{Cd}$ and $\mathrm{Pb}$, were analysed after no more than every 20 unknown samples. Because of limited sample volume, all of the samples were diluted by a factor of two with $1 \% \mathrm{HNO}_{3}$ prior to analysis.

\subsection{Quality Control}

In order to gain an insight into the within-laboratory repeatability, duplicate UBM extractions of each test material, commonly employed reference materials normally used for their total concentrations, blanks and spikes were requested from each participating laboratory. However, due to time constraints this was not possible for all participating laboratories. The reference material QC samples were either the NIST 2710 or 2711 SRM (or both where possible) and the BGS 102 As bioaccessibility guidance soil (Wragg, 2009). The blank QCs consisted of the individual 'stomach' or 'stomach \& intestine' matrix taken through the entire UBM in vitro procedure, prior to submission for analysis, to account for $\mathrm{As}, \mathrm{Cd}$ and $\mathrm{Pb}$ contamination from the chemicals and the extraction equipment in use. The spike QCs were individual $100 \mathrm{mg}^{-1}$ spiking solutions of As, Cd and $\mathrm{Pb}$, provided by the lead laboratory, with instructions for the preparation of a mixed 
spiking solution for extraction in order that each analyte was present in solution, in each phase ('stomach' or 'stomach \& intestine') at $0.1 \mathrm{mg} \mathrm{l}^{-1}$, after sample preservation. The spiking solutions were extracted with no test material present to check the percentage (\%) recovery of the extraction method, i.e. that no analyte was adsorbed to the extraction tubes or lost during the extraction procedure.

\subsection{Statistical data analysis}

The analytical performance characteristics of the bioaccessibility measurement (repeatability and reproducibility) were determined in the collaborative study using the procedure described in ISO Standard 5725-2 (ISO). Outlier testing using Grubbs' test (Grubbs, 1950) and Cochran's test (Snedecor and Cochran, 1980) were carried out in the $\mathrm{R}$ statistical programming language using the outliers package ( $\mathrm{R}$ Development Core Team, 2007) and the outlier removal rules specified in ISO Standard 5725-2 were applied. Repeatability and reproducibility calculations were carried out in MS Excel ${ }^{\mathrm{TM}}$. In addition to the ISO 5725-2 statistical calculations, the in vivo relative bioavailability data is plotted against the relative bioaccessibility data to show the relationship between the in vivo and the in vitro measurements. Linear regression analysis was carried out using Theils method (Theil, 1950; Glaister, 2005) that makes no assumption about the errors on the $\mathrm{x}$ and $\mathrm{y}$ axes and is robust to outliers. Confidence limits on the regression line were calculated using ten thousand Monte Carlo simulations using the uncertainties on the relative bioaccessible and relative bioavailable data. The procedure was implemented in the MATLAB programming language.

\section{Results}

The mean relative bioaccessibilities and associated relative standard deviations for As, Cd and $\mathrm{Pb}$ for each sample in each compartment (along with the additional data for the lower soil to solution ratio for As) are given in Tables 2 and 3.

\subsection{Quality Control}

Each participating laboratory supplied a minimum of three blank extraction samples from each of the UBM phases, under the standard $\left(1: 100 \mathrm{~g} \mathrm{ml}^{-1}\right)$ extraction conditions. For the 'stomach phase' extractions, all data for As was returned at below the limit of quantification $\left(<6.75 \mathrm{mg} \mathrm{kg}^{-1}\right)$; however, for $\mathrm{Cd}$, one data point for one laboratory was within 2 times the reporting limit $\left(<0.90 \mathrm{mg} \mathrm{kg}^{-1}\right)$ and, for $\mathrm{Pb}$ a second laboratory 
returned two blank sample values within 3 times the reporting limit $\left(<0.225 \mathrm{mg} \mathrm{kg}^{-1}\right)$. For the 'stomach \& intestine phase' all of the blank extraction samples returned values less than the reporting limit for As $\left(<17.6 \mathrm{mg} \mathrm{kg}^{-1}\right), \mathrm{Cd}\left(<2.34 \mathrm{mg} \mathrm{kg}^{-1}\right)$ and $\mathrm{Pb}(<5.85 \mathrm{mg}$ $\mathrm{kg}^{-1}$ ). Where ICP-AES values for test sample extractions were returned below the reporting limit or the increased soil to solution ratio of $1: 1000\left(\mathrm{~g} \mathrm{ml}^{-1}\right)$ was employed, the samples were analysed by ICP-MS because of its increased sensitivity and lower reporting limits. The data from the extraction blanks provides a good indication that the reagents or equipment used in the UBM methodology did not contribute $\mathrm{As}, \mathrm{Cd}$ or $\mathrm{Pb}$ to the sample data.

Six of the seven participating laboratories provided a minimum of two mixed element spike extracts for each phase of the UBM, under the standard $\left(1: 100 \mathrm{~g} \mathrm{ml}^{-1}\right)$ extraction conditions, for analysis. One laboratory was unable to provide any spike extracts. Figure 2, a box and whisker plot, summarises the range of mean percentage $\mathrm{As}, \mathrm{Cd}$ and $\mathrm{Pb}$ spike recovery values in each of the two UBM phases for the participating laboratories. Figure 2 shows that, for the 'stomach' phase of the extraction, the $\mathrm{As}, \mathrm{Cd}$ and $\mathrm{Pb}$ recovery was $105 \pm 10 \%$, and that there was a wider spread in the data for the 'stomach \& intestine' phase extractions. For As and $\mathrm{Cd}$ in the 'stomach \& intestine' phase, Figure 2 indicates an increased spread in the \% recovery of $\sim 80-110 \%$, compared with the 'stomach' phase, although both the median $\mathrm{As}$ and $\mathrm{Cd}$ recoveries of $\sim 100$ and $90 \%$ respectively are considered acceptable. The percentage spike recovery for $\mathrm{Pb}$ in the 'stomach \& intestine' phase ranges from $\sim 55$ to $105 \%$ (Figure 2 ), with a median value of $\sim 75 \%$. The behaviour of $\mathrm{Pb}$ and $\mathrm{Cd}$ is strongly $\mathrm{pH}$ dependent, with higher solubility in acidic conditions and complexation by pepsin or chemical precipitation of metals in an increased $\mathrm{pH}$ environment such as the gastro-intestinal compartment (Ellickson et al., 2001; Gron and Andersen, 2003). This is not observed in the case of elements that form anions in solution and is consistent with previous studies for As (Oomen et al., 2006). For the extractions carried out at the decreased soil:solution ratio, As spike recoveries of 100 and 99\% for the 'stomach' and 'stomach \& intestine' phases respectively were returned.

Table 4 gives a summary of the mean bioaccessible values for each element in each compartment for the quality control reference soils along with the within-laboratory repeatability and the overall between-laboratory reproducibility expressed as the relative standard deviation. This data cannot be used to check accuracy as there are no certified bioaccessible values, but they serve to give an idea of the uncertainty in the results both 
within and between laboratories for milled and well homogenised soils. BGS102 data tends to have higher within and between-laboratory variability compared with the two NIST soils. This is probably due to the relatively low concentrations of bioaccessible As, $\mathrm{Cd}$ and $\mathrm{Pb}$ in this soil. After a dilution of 100 in the extraction stage, and a further dilution of 10 in the preservation stage the $\mathrm{As}, \mathrm{Cd}$ and $\mathrm{Pb}$ concentrations in solution are likely to be at or approaching detection limits for the ICP-AES instrument used for the analysis of the extracts. For NIST 2710 and NIST 2711, the bioaccessible concentrations of $\mathrm{As}, \mathrm{Cd}$ and $\mathrm{Pb}$ are significantly higher than BGS 102 so variability from being close to detection limits should not be a problem. The variability of results for the NIST soils is inconsistent from being very good ( $\sim 3 \%$ RSD for $\mathrm{Cd}$ and $\mathrm{Pb}$ and in NIST 2711 in the stomach phase) to poor (94.6\% in NIST 2711 for $\mathrm{Pb}$ in the stomach phase). Some of the reasons for these differences are discussed in more detail in sections 4.5 to 4.7 but this exercise suggests the variability is method related and not down to sample heterogeneity.

\subsection{Total element data}

The total $\mathrm{As}, \mathrm{Cd}$ and $\mathrm{Pb}$ concentrations in the test samples were obtained from previously published data using USEPA method 3050 (Schroder et al., 2003; Schroder et al., 2004; Basta et al., 2007) given in Table 1. However, the BGS laboratories undertook trial digestions of the As samples, which when subjected to a mixed acid digestion $\left(\mathrm{HF}, \mathrm{HNO}_{3}\right.$ and $\mathrm{HClO}_{4}$ ) explosive ejections of sample and reagents from the reaction tube were observed. This indicated that the mixed acid digest employed was not suitable for these samples but served to illustrate the unusual geochemistry of these materials, thought to be due to the presence of high concentrations of elemental sulphur.

\section{3. $\quad p H$ tolerances}

The UBM protocol (Figure 1) requires that the $\mathrm{pH}$ of the individual extracts are checked at the end of the 'stomach' and 'stomach \& intestine' phases and the start of the 'stomach $\&$ intestine' extraction phase to ensure that acceptable $\mathrm{pH}$ values are achieved. Figure 3 and 4 summarise the distribution of the $\mathrm{pH}$ data obtained for the end of the 'stomach' phase of the UBM, as a box and whisker plot. Figure 3 shows that the end 'stomach' phase $\mathrm{pH}$ tolerance criteria (1.2 to 1.7$)$ for the As soils was met by the contributing laboratories for the majority of the test samples. However, for samples As 6 and 7 a wide range of $\mathrm{pH}$ values were observed, $\sim 1.2$ to 4.0 and 4.7 respectively. Outliers (denoted as solid black crosses), outside of the $\mathrm{pH}$ tolerance were observed for sample As $8(\sim \mathrm{pH}$ 2.75 and 3.5), similarly for sample As 9 ( $\mathrm{pH} 2.25$ ) in addition to the maximum value for 
this sample ( 2.0). A similar trend was observed for $\mathrm{pH}$ measurements made in both compartments during the 'stomach \& intestine' extract for the As soils (data not shown), where samples As 6 and 7 were outside of the required $\mathrm{pH}$ tolerances. For the materials contaminated with $\mathrm{Cd}$ and Pb (Figure 4), samples NBR-255B-04, NBR-256-04, NBR267-04, NBPb9 and NBPb11 all had end 'stomach' phase pH's in the range c. 4.0 - 5.0, sample BV2TM1 ranged between 1.2 and 3.25 and the maximum pH's of samples BV1A, BV1B and DNR5-1 was 1.8, for both the 'stomach' and 'stomach \& intestine' extractions. As there was a limited mass of NBR-255B-04, NBR-256-04, NBR-267-04, $\mathrm{NBPb} 9$ and $\mathrm{NBPb} 11$, these samples were only extracted by one laboratory.

\subsection{Validation and reliability of the test}

The relative bioavailability data obtained from the in vivo studies for the three elements have been obtained by taking the ratio of the amount absorbed from the soil to the amount absorbed from a completely soluble salt of the element. In order to make a meaningful comparison the absolute bioaccessibility as measured by the UBM in vitro test (amount of element extracted from the soil expressed as a percentage of the total element in the soil) was converted to a relative bioaccessibility by dividing the absolute bioaccessibility of the contaminant in the soil by the absolute bioaccessibility of the completely soluble salt. The bioaccessibility of the same salts used in the in vivo studies (As in Na-arsenate, $\mathrm{Cd}$ in $\mathrm{Cd}$ chloride and $\mathrm{Pb}$ in $\mathrm{Pb}$-acetate) were measured using the same UBM procedure used for the soils. In the gastric phase, the absolute bioaccessibility values were $99 \pm 2 \%$ and $98 \pm$ $3 \%$ for $\mathrm{Pb}$ in $\mathrm{Pb}$-acetate and $\mathrm{Cd}$ in $\mathrm{Cd}$-chloride, respectively. For $\mathrm{As}$ in Na-arsenate bioaccessibility was $95 \pm 3 \%$. This showed that all three elements were either indistinguishable or within $2 \%$ of being $100 \%$ bioaccessible for the reference compounds in this compartment. In contrast, in the intestinal phase $\mathrm{Pb}$ and $\mathrm{Cd}$ had reduced absolute bioaccessibility giving values of $66 \pm 3 \%$ and $68 \pm 3 \%$ respectively; however, the As bioaccessibility remained high at $92 \pm 4 \%$. The reasons for this are related to the solubility and stability of $\mathrm{Cd}$ and $\mathrm{Pb}$ in the higher $\mathrm{pH}$ solutions as discussed earlier (Ellickson et al., 2001; Gron and Andersen, 2003).

Table 5 gives the values of the assessment criteria (defined at the end of section 2) for each element and each of the simulated GI compartments. The grey highlighted values indicate where the required benchmark value was achieved. Figure 5 shows plots of the $\%$ relative bioavailable values versus the $\%$ relative bioaccessible values, showing error bars on both axes along with the Theil line of best fit, the $90 \%$ confidence interval for the line 
and the line of equivalence. Figure 6 summarises the within and between-laboratory RSD values.

\subsection{Arsenic}

Table 5 shows that correlation between in vitro and in vivo data is strong for both compartments, but the slope of the lines are low. Figure 5 show there are some very large uncertainty bars for some samples on both the bioavailable and bioaccessible data. Table 5 and Figures 5(a), 5(b), 6(a) and 6(b) show that although the within-laboratory repeatability meets the benchmark criteria, the between-laboratory data for both compartments does not. Figure 3 shows that samples As 6 and As 7 deviated significantly from the target $\mathrm{pH}$ range compared with the other samples which may have caused poor reproducibility. Figure 5(a), however, does not show that these samples have higher bioaccessibility uncertainties. Leaving sample As 6 and As 7 out of the calculations for benchmark data for Table 5 did not have any significant effect on the assessment criteria and the data for these two points were therefore retained. In a previous study (Basta et al., 2007) using soils As 1 to As 10 (Table 1) to test a different in vitro bioaccessibility method (the IVG method) the soils As 1 to As 4 are identified as being contaminated with a calcine waste material and samples As 6 to As 10 oxidized waste material (slag) generated from the roasting and/or smelting of arsenopyrite ore. Examination of Figure 5 ( $a$ and $b$ ) and Table 2 clearly shows that the slag samples, that have the lower total As and higher bioaccessibilities have much poorer reproducibility (high average standard deviation $\sim 12 \%$ relative bioaccessibility) compared with the calcine samples (average standard deviation $\sim 0.8 \%$ bioaccessibility) suggesting that this is caused by the geochemistry of these samples. Additional geochemical data on these samples (Rodriguez et al., 2003) shows that the calciner samples have relatively acid soil $\mathrm{pH}(2.6-3.1)$ and low Ca concentrations (11.7-18 $\mathrm{g} \mathrm{kg}^{-1}$ ) compared with the slag soils (soil $\mathrm{pH}$ 7.1-7.4 and Ca concentrations of $60.7-121 \mathrm{~g} \mathrm{~kg}^{-1}$ ). The samples with the highest Ca concentrations (As 6 and As 7, 121 and $96.4 \mathrm{~g} \mathrm{~kg}^{-1}$ respectively) are the samples with the poorly controlled $\mathrm{pH}$ tolerance for the 'stomach' phase of the UBM (Figure 3). This suggests that the poorer between-laboratory reproducibility on the iron slag samples is a function of their high buffering capacity highlighting the need for tighter control limits on the 'stomach' phase. Comparing the absolute \% bioaccessibilities, obtained by the UBM with the IVG previous study (a method that uses a soil to solution ratio of 1:150, a stomach $\mathrm{pH}$ of 1.8 for $1 \mathrm{hr}$ and an intestinal ph of 5.5 for $1 \mathrm{hr}$ ) shows that there is very good agreement between the two data sets. For the 'stomach' compartment (a simple 
linear regression with the UBM on the $\mathrm{x}$-axis and IVG on the $\mathrm{y}$ axis gives rsquare $=0.99$, slope $=1.15$ and intercept-2.2). For the 'stomach \& intestine' compartment, however, agreement is poor (rsquare $=0.38$, slope $=2.3$, intercept $=-2.6$ ) this is probably due to the lower $\mathrm{pH}$ (5.5) and shorter reaction time used in the IVG method.

In summary, the data for the $1: 100 \mathrm{~g} \mathrm{ml}^{-1}$ soil:solution ratio for these test materials appear to show poor reproducibility for the slag samples and low relative bioaccessibility values as compared with the relative bioavailability (Figures 5(a) and Figure 5(b) but the stomach compartment data show close agreement with an independent bioaccessibility test. Additional extractions at the lower soil to solution ratio (1:1000 g ml-1) were carried out on nine of the original samples (the two Aberjona river samples were not extracted at this lower soil to solution ratio due to lack of material). At the lower ratio there was much improved agreement with relative bioavailability.. The r-square values in Table 5 for this ratio indicate a strong correlation with relative bioavailable As, with the slopes of the lines meeting the benchmark criteria. Figures 5(c) and 5(d) show the uncertainties on the bioaccessibility values to be much reduced compared with the $1: 100 \mathrm{~g} \mathrm{ml}^{-1}$ solid to liquid ratio, although only two laboratories have contributed data for the high dilution conditions. Table 5 and Figures 6(c) and 6(d) show that the within-laboratory repeatability meets the benchmark criteria for both the 'stomach' and 'stomach \& intestine' compartments. Under these conditions these results would indicate that the UBM method would be fit for purpose.

\subsection{Cadmium}

For Cd there are comparative data (Schroder et al., 2003) for five of the soils ( $\mathrm{Nb} \mathrm{Cd1,}$ NBR-255B-04, NBR-256-04, NBR-261-04, NBR-267-04) using the IVG bioaccessibility method discussed in Section 4.5. In a similar manner to As, for the 'stomach' compartment there is a strong 1:1 relationship with the UBM data (a simple linear regression with the UBM on the $\mathrm{x}$-axis and OSU-IVG on the y axis gives rsquare $=0.86$, slope $=0.97$ and intercept $=-0.4$ ). For the 'stomach \& intestine' compartment both methods give lower values than their equivalent 'stomach compartments' (t-test p-value $<0.005$ ) and there is a strong correlation between the UBM and the OSU-IVG although the latter gives, on average, lower values than the former (a simple linear regression with the UBM on the $\mathrm{x}$-axis and OSU-IVG on the $\mathrm{y}$ axis gives rsquare $=0.71$, slope $=0.59$ and intercept $=4.3$ ). 
Table 5 shows a strong correlation of relative bioaccessible $\mathrm{Cd}$ with relative bioavailable $\mathrm{Cd}$ in the stomach compartment but the slope of the line is 0.63 which does not meet the benchmark criteria although this value is in agreement with the slope of the bioaccessibility vs relative bioavailability plot (0.60) using the OSU-IVG method (Schroder et al., 2003). Figure 5 shows the error bars on the on the relative bioaccessibility values to be less than the relative bioavailability error bars. Table 5 and Figure 5(e) show that the within and between-laboratory repeatability meet the benchmark criteria for the 'stomach' compartment. For the 'stomach \& intestine' compartment, however, Table 5 and Figures 5(f) and 6(f) show that the slope, r-square, repeatability and reproducibility are degraded, so that all but the within-laboratory RSD fail the benchmark criteria. Under these conditions these results would indicate that, apart from the preferred slope of $>0.8$, the UBM method would be fit for purpose for the 'stomach' phase but not the 'stomach \& intestine' phase. The decreased slope of the regression line and the poorer reproducibility in the 'stomach \& intestine' phase is probably related to the higher $\mathrm{pH}$ in this compartment. Cadmium solubility decreases at high pH (Cotton et al., 1999), the spike recovery (Figure 2) shows that $\mathrm{Cd}$ is lost to precipitation at $\mathrm{pH} 6.3$ and complexation by pepsin in the gastro-intestinal compartment (Ellickson et al., 2001; Gron and Andersen, 2003), and similarly Cd extracted from the soil - at pH 1.2 will undergo the same processes in the 'stomach \& intestine' phase. In addition, the soil also provides a sink for sorption at the higher $\mathrm{pH}$ conditions which is dependent on individual soil properties. These include the amount of organic matter, clays and $\mathrm{Al}$ and $\mathrm{Fe}$ oxides present in the soil. All of these can act as sites for specific adsorption at neutral to alkaline $\mathrm{pH}$ (Cave et al., 2011). All of these effects result in a lower slope and poorer reproducibility.

\subsection{Lead}

Table 5 shows that the slope of the line for the 'stomach' compartment is only just below the benchmark criteria (0.78 compared with a target of 0.8$)$ and the correlation with bioavailable $\mathrm{Pb}$ is within the criterion. Examination of Figure 5(g) and 5(h) and Table 3 shows two groupings in the data, a set of 6 samples with relative bioaccessibilities of $10 \%$ or less and a set of 6 samples with relative bioaccessibilities $40 \%$ or greater. The former group of 6 samples are those that were only available to one laboratory and only have very low relative bioaccessibilities compared with their relative bioavailabilities. Figure 4 shows that $\mathrm{pH}$ at the end of the 'stomach' phase was much higher than specified in the 
procedure and this may account for the low bioaccessibility values in these samples. This hypothesis is also supported by comparison of the absolute bioaccessibility values from this study with the absolute bioaccessibility values obtained for these six soils using the IVG method (Schroder et al., 2004), which, unlike As and Cd, has poor correlation and very low values compared with the IVG stomach compartment. A simple linear regression with the UBM on the $\mathrm{x}$-axis and $\mathrm{IVG}$ on the $\mathrm{y}$ axis gives rsquare $=0.19$, slope $=2.3$ and intercept $=14.2$. There are no literature bioaccessibility data for comparison of the samples with relative bioaccessibilities $>40 \%$ that were extracted by all participating laboratories. These samples, however, have relative bioaccessibilities which are more comparable to the relative bioavailability data (Figure $5(\mathrm{~g})$ ). Figure $6(\mathrm{~g})$ and Table 5 show that the within-laboratory repeatabilities for the stomach compartments are well within the benchmark criteria but the between-laboratory reproducibility is poor.

Table 5 and Figures 5(h) and 6(h) show that none of the benchmark criteria are met for the 'stomach \& intestine' compartment. The groupings observed in the 'stomach' compartment data are also seen in the 'stomach \& intestine' compartment although less pronounced. The poor reproducibility and low slope at the higher $\mathrm{pH}$ of the 'stomach $\&$ intestine' are likely to be due the same effects described for $\mathrm{Cd}$.

\section{Discussion}

For As, the low inter-laboratory RSDs and the high between-laboratory RSDs suggest that the small differences between the way the test is applied to these soils has a large effect on the results obtained. These soils have a complex physico-chemical composition and contain very high concentrations of As (Table 1) arising from the mining slag which forms a major part of their mass, which appears to contribute to the reproducibility problems observed in the inter-laboratory trial. This can also be seen in the very high uncertainty in the in vivo measurements (Figures 5(a) to 5(d)). Variability in bioaccessible As can be reduced by careful control of in vitro $\mathrm{pH}$ which has been shown to greatly affect the measured metal bioaccessibility (Oomen et al., 2002; Yang et al., 2003; Waisberg et al., 2004; Tang et al., 2006; Tang et al., 2007; Tang et al., 2008). However, $\mathrm{pH}$ cannot be controlled during in vivo dosing trials used to calculate the relative bioavailability of As in soil. Although the higher dilution test (soil to liquid ratio 1:1000 $\mathrm{g} \mathrm{ml}^{-1}$ ) was only carried out at two laboratories the soils produce results which 
meet the benchmark criteria. Possible reasons why the higher dilution gives better results are:

i) The higher dilution removes the problem of As oversaturation which may be the cause of the low slope and poorer reproducibility at low dilution;

ii) At the higher dilution matrix effects (dissolution of concomitant chemical species from the sample, which adversely affect the chemical analysis) from the mine waste material are reduced.

The drawback with using the $1: 1000 \mathrm{~g} \mathrm{ml}^{-1}$ soil to liquid ratio is that the small amount of sample may cause reproducibility problems if the test soil is inhomogeneous and, if soils with lower contamination concentrations are tested, the higher dilution may bring the concentrations of the analyte near to or below the method detection limit.

In practical terms, contaminated materials that are relevant to human exposure scenarios where bioaccessibility measurements will have a significant effect on the risk assessment are soils with contaminants close to human health guideline values and not very highly contaminated mine wastes and slags similar to those assessed in this study. When considering these soils, concentration of As will be far lower and the matrix effects much reduced and the problems encountered here are likely to be much reduced. However, it is recognised that mine waste contaminated soils are important in human health risk assessments and that in these cases it may be more appropriate to use the $1: 1000 \mathrm{~g} \mathrm{ml}^{-1}$ soil to liquid ratio.

For Cd, the method meets all but the slope criteria for the specified benchmarks for the 'stomach' phase (Table 5). The low slope and poor repeatability/reproducibility observed in the 'stomach \& intestine' phase suggests that the $\mathrm{Cd}$ is precipitated out of solution at high $\mathrm{pH}$ causing the poor performance.

The $\mathrm{Pb}$ data in the 'stomach' compartment for the samples extracted by all the laboratories shows reasonable agreement with the in vivo data but all of these soils have high relative bioavailable values $(>50 \%)$. The relative bioaccessibility data from the samples with lower relative bioavailabilities is questionable because of the 'stomach' phase tolerances not being met on these samples. Table 5 shows $\mathrm{Pb}$ in the 'stomach' phase fits the rsquare and within-laboratory RSD criteria, and is only just outside the slope criteria $(0.78$, should be $\geq 0.8)$ and the between-laboratory RSD criteria $(22.78$, 
should be $\leq 20$ ). For the 'stomach \& intestine' phase none of the criteria are met which, like $\mathrm{Cd}$, suggests that precipitation at high $\mathrm{pH}$ causes the poor performance.

This study suggests that $\mathrm{pH}$ control is a critical factor for obtaining between-laboratory reproducibility. Using tighter $\mathrm{pH}$ tolerance on the stomach phase $(1.20 \pm 0.05)$, Caboche (2009) has shown that the UBM correlates well with in vivo swine data for $\mathrm{As}, \mathrm{Cd}$ and $\mathrm{Pb}$ on 15 soils with different contamination histories (r-square values $>0.89$ and slopes not significantly different from 1). In this study, the repeatability of the average relative bioaccessible measurements for the 15 soils for the 'stomach' and the 'stomach \& intestine' compartments were c. $8 \%$ and $10 \%$ RSD for As, c. 6 and $7 \%$ for $\mathrm{Cd}$ and c.5\% and $5 \%$ for $\mathrm{Pb}$. Using the UBM with a stomach phase at $\mathrm{pH} 1.5 \pm 0.05$ on smelter contaminated agricultural topsoils (Pelfrene et al., 2011), repeatabilities for the 'stomach' and the 'stomach \& intestine' compartments of 1.5 and 2.2\% RSD for Cd and 1.2 and 2.2\% RSD for $\mathrm{Pb}$ were demonstrated on 4 selected soils. These soils had absolute bioaccessible $\mathrm{Cd}$ values in the range of $0.8-24.7 \mathrm{mg} \mathrm{kg}^{-1}$ and $\mathrm{Pb}$ absolute bioaccessible values in the range of $84-1880 \mathrm{mg} \mathrm{kg}^{-1}$. Although not a true reproducibility study, the same authors demonstrated between operator repeatabilities for the 'stomach' and the 'stomach \& intestine' compartments of 3.4\% and 15.2\% RSD for Cd and $11.0 \%$ and $6.5 \%$ $\mathrm{RSD}$ for $\mathrm{Pb}$ using the same subset of soils. Without tighter $\mathrm{pH}$ control (stomach $\mathrm{pH} 1.2-$ 1.4), a study of urban soils contaminated from $\mathrm{Pb}, \mathrm{Zn}$ smelters (Roussel et al.2010) showed repeatabilities for the UBM method for the 'stomach' and the 'stomach \& intestine' compartments of $6.3 \%$ and $13.8 \%$ RSD for Cd and $12.0 \%$ and $17.4 \%$ RSD for $\mathrm{Pb}$ for the NIST 2710 standard reference material $(\mathrm{n}=25)$. Whilst these studies are not directly comparable, there is some evidence that the studies (Caboche, 2009; Pelfrene et al., 2011) with tighter controls on the stomach $\mathrm{pH}$ have better repeatabilities than the study (Roussel et al. 2010)with wider pH limits ( $<10 \%$ compared with 6-17\% RSD) thus supporting the findings of this study. The between operator study (Pelfrene et al., 2011), although not strictly comparable to a between-laboratory comparison, shows RSD values $<20 \%$, again suggesting that the benchmark criteria of $<20 \%$ RSD should be obtainable with careful control on the method.

The overall purpose of a bioaccessibility test is to provide information for risk assessors on the amount of PHE will be taken into the body via the ingestion route. A validation study comparing in vitro and in vivo data is, in effect, calibrating the bioaccessibility against bioavailability data so that the more easily obtained bioaccessibility values can be 
used to predict bioavailability. There are a number of uncertainties in relating a bioaccessible value to the amount of PHE absorbed by a human subject. If we assume the swine gastrointestinal model is a good surrogate for humans (Miller and Ullrey, 1987; Moughan et al., 1992) and that there is a linear relationship between bioaccessibility and bioavailability (Schroder et al., 2003; Schroder et al., 2004; Drexler and Brattin, 2007; Juhasz et al., 2007a) then the data from this and similar studies can be used to provide information on the reliability of the data provided to the risk assessor. A simulation was set up using relative bioavailability data on a set of theoretical soils covering the range of 1 to $90 \%(1,5,25,50,75$ and $90 \%)$ with theoretical relative bioaccessibility data on the same soil samples. The simulation used a linear model with slope of unity and intercept of zero where bioavailability is to be predicted from bioaccessibility. The uncertainties are normally distributed on both parameters ranging from 5\% to 20\% RSD. A Monte Carlo simulation was set up to estimate the uncertainties on the predicted bioavailability. The linear models for the slope and intercept were created using Theils method (Theil, 1950; Glaister, 2005) that accommodates errors on both the $\mathrm{x}$ and $\mathrm{y}$ axes. The results are shown in Figure 6 with error bars indicating 95\% confidence intervals. At 5\% RSD uncertainty on the bioaccessibility and bioavailability data used for the calibration all of the five bioavailability predictions $(1,5,25,75$ and $90 \%$ relative bioavailability) are all clearly distinguishable. At $10 \%$ RSD uncertainty the two highest and lowest predicted values have overlapping error bars but the intermediate bioavailability values are still clearly distinguishable. For $20 \%$ RSD uncertainty the overlap between the predicted values increases again but it is still possible to distinguish between $5 \%, 25 \%$ and $75 \%$ predicted bioavailability. In this study a reproducibility target of $20 \%$ has been set; however, Figure 6 shows that the majority of within-laboratory RSD (method repeatability) are better than $10 \%$ and therefore with more careful specification of the test (particularly $\mathrm{pH}$ control) it should be possible to approach 10\% RSD reproducibility. This simulation clearly shows that $20 \%$ reproducibility is the maximum tolerable in order to provide useful data for risk assessment.

The simulation also requires that the in vivo bioavailability data should also be better than $20 \%$ RSD which may be more difficult to control. Figure 5 shows that the uncertainties on the bioavailability data are in many cases much higher than the bioaccessibility values and therefore improved in vivo data is also required to provide robust validation. The uncertainty simulation clearly shows that improvements in the reproducibility of both the 
in-vivo and in-vitro measurements are required to give risk assessors more confidence in the use of bioaccessibility data.

\section{Conclusion}

In terms of meeting the five main criteria for the bioaccessibility test (listed in section 1), the UBM is physiologically based with one set of extraction reagents used for the three elements considered in this study. The As bioaccessibility measurements, however, required a lower solid to liquid ratio than for $\mathrm{Cd}$ and $\mathrm{Pb}$. It is envisaged that this will not be necessary for contaminated soils with As concentrations that are more relevant to human exposure scenarios. The correlations between the in vivo data and the in vitro data suggest that the UBM is a good analogue of in vivo conditions although there is a need to improve the repeatability and reproducibility of the method before this can be clearly demonstrated. The test uses fasted conditions (low stomach $\mathrm{pH}$ with no food present) and is therefore likely to give conservative (high bioaccessible values) results, which has been confirmed by an independent study (Caboche, 2009) using a comparison against an invivo swine model.. The UBM method does, however, agree well with the IVG in vitro test for $\mathrm{As}$ and $\mathrm{Cd}$ in the stomach compartments where data for the same soils are available. The IVG method has been validated against swine data for $\mathrm{As}, \mathrm{Cd}$ and $\mathrm{Pb}$ (Schroder et al., 2003; Schroder et al., 2004; Basta et al., 2007).

This study and others (Roussel et al.,2010; Caboche, 2009; Pelfrene et al., 2011)that use the UBM have highlighted a number of specific aspects of the UBM test that need to be addressed. There needs to be a review of the practical procedures used in the in vitro test to improve the between-laboratory repeatability. Previous studies have shown the importance of $\mathrm{pH}$ of the 'stomach' compartment on the final bioaccessibility result (Oomen et al., 2002). It is possible that the $\mathrm{pH}$ tolerance for the UBM is too wide. This is probably one of the main sources of between-laboratory variability in this study.

For As, it appears that the method will meet the benchmark criteria for both 'stomach' and 'stomach \& intestine' compartments if soils with lower As concentrations (tens to hundreds of $\mathrm{mg} \mathrm{kg}^{-1}$ ) and with a less complex physico-chemical make up are used. For $\mathrm{Cd}$ and $\mathrm{Pb}$ it seems possible that the method will work for the 'stomach' phase but not for the 'stomach \& intestine' phase; A further follow up study/inter-laboratory trial using test soils with contaminant concentrations more relevant to bioaccessibility testing (e.g. up to 5 times soil guideline values) is required; The As soils provided by Professor Basta have a complex physico-chemical composition, which appears to contribute to the 
reproducibility problems observed in the inter-laboratory trial; A more rigorous in vivo validation using fasted conditions of the UBM is required; It is not unusual for the first inter-laboratory trial of a new operationally defined procedure for extracting metals from soils to have some initial problems e.g. Quevauviller (2002), which is indeed the case for the UBM method. However, the data indicate that, in general, this in vitro test provides bioaccessibility data which is comparable data to in vivo bioavailability data. The study has highlighted areas of the test which require further refinement but it is our view that with further development this procedure provides a basis for a standardised bioaccessibility test for PHEs in soils.

\section{Acknowledgements}

This paper is published with the permission of the Executive Director of the British Geological Survey.

\section{References}

Guidance for industry extended release oral dosage forms: Development, evaluation, and application of in vitro/in vivo correlations. U.S. Department of Health and Human Services Food and Drug Administration, 1997.

Estimation of relative bioavailability of lead in soil and soil-like materials using in vivo and in vitro methods. Office of Solid Waste and Emergency Response U.S. Environmental Protection Agency, Washington, DC 20460, 2007.

Albores AF, Cid BP, Gomez EF, Lopez EF. Comparison between sequential extraction procedures and single extractions for metal partitioning in sewage sludge samples. Analyst 2000; 125: 1353-1357.

ATSDR. Toxicological profile for arsenic. Agency for Toxic Substances and Disease Registry, 2007a.

ATSDR. Toxicological profile for lead. Agency for Toxic Substances and Disease Registry, $2007 \mathrm{~b}$.

ATSDR. Draft toxicological profile for cadmium Agency for Toxic Substances and Disease Registry, 2008.

Bannon DI, Drexler JW, Fent GM, Casteel SW, Hunter PJ, Brattin WJ, et al. Evaluation of small arms range soils for metal contamination and lead bioavailability. Environ Sci Technol 2009; 43: 9071-9076.

Basta NT, Foster JN, Dayton EA, Rodriguez RR, Casteel SW. The effect of dosing vehicle on arsenic bioaccessibility in smelter-contaminated soils. J Environ Sci Health, Part A 2007; 42: 1275 - 1281.

Beak DG, Basta NT, Scheckel KG, Traina SJ. Linking solid phase speciation of pb sequestered to birnessite to oral $\mathrm{pb}$ bioaccessibility: Implications for soil remediation. Environ Sci Technol 2008; 42: 779-785.

Bosso ST, Enzweiler J. Bioaccessible lead in soils, slag, and mine wastes from an abandoned mining district in brazil. Environ Geochem Health 2008; 30: 219-229.

Bosso ST, Enzweiler J, Angelica RS. Lead bioaccessibility in soil and mine wastes after immobilization with phosphate. Water Air Soil Pollut 2008; 195: 257-273. 
Caboche J. Validation d'un test de mesure de bioaccessibilité. Application à quatre éléments traces métallique dans les sols: $\mathrm{As}, \mathrm{Cd}, \mathrm{Pb}$ et $\mathrm{Sb}$. Science Agronomique. PhD. L'Institut National Polytechnique de Lorraine, Nancy, 2009, pp. 348.

Caboche J, Denys S, Feidt C, Delalain P, Tack K, Rychen G. Modelling pb bioaccessibility in soils contaminated by mining and smelting activities. J Environ Sci Health, Part A 2010; 45: 1264-1274.

Cave M, Taylor H, Wragg J. Estimation of the bioaccessible arsenic fraction in soils using near infrared spectroscopy. Journal of Environmental Science and Health, Part A 2007; 42: 1293 - 1301.

Cave MR, Wragg J. Determination of major and trace cations in aqueous samples by inductively coupled plasma atomic emission spectrometry (varian/vista). British Geological Survey, 2002, pp. 1-18.

Cave MR, Wragg J, Denys S, Jondreville C, Feidt C. Oral bioavailability. In: Swartjes F, editor. Dealing with contaminated sites: From theory towards practical application. Springer, 2011.

Cave MR, Wragg J, Palumbo B, Klinck BA. Measurement of the bioaccessibility of arsenic in uk soils. Environment Agency, 2003.

Chan DY, Black WD, Hale BA. Cadmium bioavailability and bioaccessibility as determined by in vitro digestion, dialysis and intestinal epithelial monolayers, and compared with in vivo data. J Environ Sci Health, Part A 2007; 42: 1283 - 1291.

Cotton FA, Wilkinson G, Murillo CA, M B. Advanced inorganic chemistry. New York: John Wiley and Sons, 1999.

Datta R, Makris KC, Sarkar D. Arsenic fractionation and bioaccessibility in two alkaline texas soils incubated with sodium arsenate. Arch Environ Contam Toxicol 2007; 52: 475-482.

Dean JR, Ma RL. Approaches to assess the oral bioaccessibility of persistent organic pollutants: A critical review. Chemosphere 2007; 68: 1399-1407.

Demetriades A, Xiangdong L, Ramsey MH, Thornton I. Chemical speciation and bioaccessibility of lead in surface soil and house dust, lavrion urban area, attiki, hellas. Environmetal Geochemistry and Health 2010; 36: 529-552.

Drexler JW, Brattin WJ. An in vitro procedure for estimation of lead relative bioavailability: With validation. Hum Ecol Risk Assess 2007; 13: 383-401.

Ellickson KM, Meeker RJ, Gallo MA, Buckley BT, Lioy PJ. Oral bioavailability of lead and arsenic from a nist standard reference soil material. Arch Environ Contam Toxicol 2001; 40: 128-135.

Emami J. In vitro - in vivo correlation: From theory to applications. Journal of Pharmaceutical Science 2006; 9: 169-189.

Environment Agency. Bioaccessibility testing. Questions and answers. In: Agency E, editor, 2005a.

Environment Agency. Environment agency's science update on the use of bioaccessibility testing in risk assessment of land contamination. In: Agency E, editor, $2005 \mathrm{~b}$.

Environment Agency. In-vitro bioaccessisbility testing: Current science and way forward (Environment Agency science update 2). In: Agency E, editor, 2007.

Fendorf S, La Force MJ, Li GC. Temporal changes in soil partitioning and bioaccessibility of arsenic, chromium, and lead. J Environ Qual 2004; 33: 20492055.

Finzgar N, Tlustos P, Lestan D. Relationship of soil properties to fractionation, bioavailability and mobility of lead and zinc in soil. Plant Soil Environ 2007; 53: 225-238. 
Freeman GB, Johnson JD, Killinger JM, Liao SC, Davis AO, Ruby MV, et al. Bioavailability of arsenic in soil impacted by smelter activities following oraladministration in rabbits. Fundam Appl Toxicol 1993; 21: 83-88.

Freeman GB, Johnson JD, Killinger JM, Liao SC, Feder PI, Davis AO, et al. Relative bioavailability of lead from mining waste soil in rats. Fundam Appl Toxicol 1992; 19: 388-398.

Freeman GB, Schoof RA, Ruby MV, Davis AO, Dill JA, Liao SC, et al. Bioavailability of arsenic in soil and house dust impacted by smelter activities following oral administration in cynomolgus monkeys. Fundam Appl Toxicol 1995; 28: 215-222.

Gal J, Hursthouse A, Cuthbert S. Bioavailability of arsenic and antimony in soils from an abandoned mining area, glendinning (sw scotland). J Environ Sci Health, Part A 2007; 42: 1263 - 1274.

Gasser UG, Walker WJ, Dahlgren RA, Borch RS, Burau RG. Lead release from smelter and mine waste impacted materials under simulated gastric conditions and relation to speciation. Environ Sci Technol 1996; 30: 761-769.

Girouard E, Zagury GJ. Arsenic bioaccessibility in cca-contaminated soils: Influence of soil properties, arsenic fractionation, and particle-size fraction. Sci Total Environ 2009; 407: 2576-2585.

Glaister P. Robust linear regression using theil's method. Journal of Chemical Education 2005; 82: 1472-1473.

Golub MS, Keen CL, Commisso JF, Salocks CB, Hathaway TR. Arsenic tissue concentration of immature mice one hour after oral exposure to gold mine tailings. Environ Geochem Health 1999; 21: 199-209.

Gron C, Andersen L. Human bioaccessibility of heavy metals and pah from soil. Danish Environmental Protection Agency, 2003.

Gron C, Oomen A, Weyand E, Wittsiepe J. Bioaccessibility of PAH from Danish soils. J Environ Sci Health, Part A 2007; 42: 1233 - 1239.

Grubbs FE. Sample criteria for testing outlying observations. Ann Math Stat 1950; 21: 27-58.

Hansen JB, Oomen AG, Edelgaard I, Gron C. Oral bioaccessibility and leaching: Tests for soil risk assessment. Eng Life Sci 2007; 7: 170-176.

ISO. 5725-2:1994,Accuracy (trueness and precision) of measurement methods and results. Part2: Basic method for the determination of repeatability and reproducibility of a standard measurement method.

Juhasz AL, Smith E, Weber J, Naidu R, Rees M, Rofe A, et al. Effect of soil ageing on in vivo arsenic bioavailability in two dissimilar soils. Chemosphere 2008; 71: 21802186.

Juhasz AL, Smith E, Weber J, Rees M, Rofe A, Kuchel T, et al. Comparison of in vivo and in vitro methodologies for the assessment of arsenic bioavailability in contaminated soils. Chemosphere 2007a; 69: 961-966.

Juhasz AL, Smith E, Weber J, Rees M, Rofe A, Kuchel T, et al. In vitro assessment of arsenic bioaccessibility in contaminated (anthropogenic and geogenic) soils. Chemosphere 2007b; 69: 69-78.

Juhasz AL, Weber J, Naidu R, Gancarz D, Rofe A, Todor D, et al. Determination of cadmium relative bioavailability in contaminated soils and its prediction using in vitro methodologies. Environ Sci Technol 2010; 44: 5240-5247.

Juhasz AL, Weber J, Smith E, Naidu R, Marschner B, Rees M, et al. Evaluation of sbrcgastric and SBRC-intestinal methods for the prediction of in vivo relative lead bioavailability in contaminated soils. Environ Sci Technol 2009a; 43: 4503-4509. 
Juhasz AL, Weber J, Smith E, Naidu R, Rees M, Rofe A, et al. Assessment of four commonly employed in vitro arsenic bioaccessibility assays for predicting in vivo relative arsenic bioavailability in contaminated soils. Environ Sci Technol 2009b; 43: 9487-9494.

Koch I, Duso A, Haug C, Miskelly C, Sommerville M, Smith P, et al. Distinguishing between naturally and anthropogenically elevated arsenic at an abandoned arctic military site. Environmental Forensics 2005; 6: 335-344.

Laird BD, Van de Wiele TR, Corriveau MC, Jamieson HE, Parsons MB, Verstraete W, et al. Gastrointestinal microbes increase arsenic bioaccessibility of ingested mine tailings using the simulator of the human intestinal microbial ecosystem. Environ Sci Technol 2007; 41: 5542-5547.

Latawiec AE, Simmons P, Reid BJ. Decision-makers' perspectives on the use of bioaccessibility for risk-based regulation of contaminated land. Environ Int 2010; 36: 383-389.

Ljung K, Oomen A, Duits M, Selinus O, Berglund M. Bioaccessibility of metals in urban playground soils. J Environ Sci Health, Part A 2007; 42: 1241 - 1250.

Maddaloni M, Lolacono N, Manton W, Blum C, Drexler J, Graziano J. Bioavailability of soilborne lead in adults, by stable isotope dilution. Environ Health Perspect 1998; 106: 1589-1594.

Makris KC, Quazi S, Nagar R, Sarkar D, Datta R, Sylvia VL. In vitro model improves the prediction of soil arsenic bioavailability: Worst-case scenario. Environ Sci Technol 2008; 42: 6278-6284.

Marschner B, Welge P, Hack A, Wittsiepe J, Wilhelm M. Comparison of soil Pb in vitro bioaccessibility and in vivo bioavailability with $\mathrm{Pb}$ pools from a sequential soil extraction. Environ Sci Technol 2006; 40: 2812-2818.

Meunier L, Walker SR, Wragg J, Parsons MB, Koch I, Jamieson HE, et al. Effects of soil composition and mineralogy on the bioaccessibility of arsenic from tailings and soil in gold mine districts of nova scotia. Environ Sci Technol 2010; 44: 26672674.

Miller ER, Ullrey DE. The pig as a model for human nutrition. Annual Review of Nutrition 1987; 7: 361-82.

Morman SA, Plumlee GS, Smith DB. Application of in vitro extraction studies to evaluate element bioaccessibility in soils from a transect across the United States and Canada. Appl Geochem 2009; 24: 1454-1463.

Morrison AL, Gulson BL. Preliminary findings of chemistry and bioaccessibility in base metal smelter slags. Sci Total Environ 2007; 382: 30-42.

Moseley RA, Barnett MO, Stewart MA, Mehlhorn TL, Jardine PM, Ginder-Vogel M, et al. Decreasing lead bioaccessibility in industrial and firing range soils with phosphate-based amendments. J Environ Qual 2008; 37: 2116-2124.

Moughan PJ, Birtles MJ, Cranwell PD, Smith WC, Pedraza M. The piglet as a model animal for studying aspects of digestion and absorption in milk-fed human infants. World Reveiw of Nutrition and Dietetics 1992; 67: 40-113.

Nagar R, Sarkar D, Makris KC, Datta R, Sylvia VL. Bioavailability and bioaccessibility of arsenic in a soil amended with drinking-water treatment residuals. Arch Environ Contam Toxicol 2009; 57: 755-766.

Nagourney SJ, Wilson SA, Buckley B, Kingston HMS, Yang SY, Long SE. Development of a standard reference material for $\mathrm{Cr}(\mathrm{vi})$ in contaminated soil. $\mathrm{J}$ Anal At Spectrom 2008; 23: 1550-1554. 
Nathanail CP, McCaffrey C, Haynes D. Assessing exposure to pedogenic arsenic contamination at a dwelling in northamptonshire, uk: A case study. Soil Use And Management 2005; 21: 508-517.

Nathanail CP, Smith R. Incorporating bioaccessibility in detailed quantitative human health risk assessments. J Environ Sci Health, Part A 2007; 42: 1193 - 1202.

Oomen AG. Determination of oral bioavailability of soil-borne contaminants. University of Utrecht, 2000.

Oomen AG, Brandon EFA, Swartjes FA, Lijzen JPA, Sips A. How can information on oral bioavailability improve human health risk assessment for lead-contaminated soils? Implementation and scientific basis. Epidemiology 2006; 17: S40-S40.

Oomen AG, Hack A, Minekus M, Zeijdner E, Cornelis C, Schoeters G, et al. Comparison of five in vitro digestion models to study the bioaccessibility of soil contaminants. Environ Sci Technol 2002; 36: 3326-3334.

Palumbo-Roe B, Cave MR, Klinck BA, Wragg J, Taylor H, O'Donnell K, et al. Bioaccessibility of arsenic in soils developed over jurassic ironstones in eastern england. Environ Geochem Health 2005; 27: 121-130.

Palumbo-Roe B, Klinck B. Bioaccessibility of arsenic in mine waste-contaminated soils: A case study from an abandoned arsenic mine in SW England (UK). J Environ Sci Health, Part A 2007; 42: 1251 - 1261.

Pelfrene A, Waterlot C, Mazzuca M, Nisse C, Bidar G, Francis D. Assessing Cd, Pb, Zn human bioaccessibility in smeltercontaminated agricultural topsoils (Northern France). Environ Geochem Health 2011.

Poggio L, Vrscaj B, Schulin R, Hepperle E, Marsan FA. Metals pollution and human bioaccessibility of topsoils in Grugliasco (Italy). Environ Pollut 2009; 157: 680689.

Quevauviller P. Operationally-defined extraction procedures for soil and sediment analysis. Part 3: New CRMs for trace-element extractable contents. Trends in Analytical Chemistry 2002; 21: 774-785.

R Development Core Team. R: A language and environment for statistical computing. $\mathrm{R}$ Foundation for Statistical Computing, 2007.

Razo I, Tellez J, Carrizales L, Castro J, Diaz-Barriga F, Monroy M. Mineralogical control on As bioaccessibility in high polluted soils from an old mining-metallurgical site in mexico. Abstr Pap Am Chem Soc 2006; 231: 30-ENVR.

Richardson $\mathrm{M}$. What regulators look for in adopting new science into regulatory policythe case of risk assessment and bioavailability/bioaccessibility of contaminants in soil. Epidemiology 2008; 19: S30-S30.

Rieuwerts JS, Searle P, Buck R. Bioaccessible arsenic in the home environment in Southwest England. Sci Total Environ 2006; 371: 89-98.

Rodriguez RR, Basta NT, Casteel S, Pace L. An in vitro gastrointestinal method to estimate bioavailable arsenic in contaminated soils and solid media. Environ Sci Technol 1999; 33: 642-649.

Rodriguez RR, Basta NT, Casteel SW, Armstrong FP, Ward DC. Chemical extraction methods to assess bioavailable arsenic in soil and solid media. J Environ Qual 2003; 32: 876-884.

Romero FM, Villalobos M, Aguirre R, Gutierrez ME. Solid-phase control on lead bioaccessibility in smelter-impacted soils. Arch Environ Contam Toxicol 2008; 55: 566-575.

Roussel H, Waterlot C, Pelfrene A, Pruvot C, Mazzuca M, Douay F. Cd, Pb and Zn oral bioaccessibility of urban soils contaminated in the past by atmospheric emissions 
from two lead and zinc smelters. Arch Environ Contam Toxicol;2010 58: 945954.

Roussel H, Waterlot C, Pelfrene A, Pruvot C, Mazzuca M, Douay F. Cd, Pb and $\mathrm{Zn}$ oral bioaccessibility of urban soils contaminated in the past by atmospheric emissions from two lead and zinc smelters. Arch Environ Contam Toxicol 2010; 58: 945-54.

Ruby MV, Davis A, Link TE, Schoof R, Chaney RL, Freeman GB, et al. Development of an in-vitro screening-test to evaluate the in- vivo bioaccessibility of ingested mine-waste lead. Environ Sci Technol 1993; 27: 2870-2877.

Ruby MV, Davis A, Schoof R, Eberle S, Sellstone CM. Estimation of lead and arsenic bioavailability using a physiologically based extraction test. Environ Sci Technol 1996; 30: 422-430.

Saikat S, Barnes B, Westwood D. A review of laboratory results for bioaccessibility values of arsenic, lead and nickel in contaminated uk soils. J Environ Sci Health, Part A 2007; 42: 1213 - 1221.

Sarkar D, Quazi S, Makris KC, Datta R, Khairom A. Arsenic bioaccessibility in a soil amended with drinking-water treatment residuals in the presence of phosphorus fertilizer. Arch Environ Contam Toxicol 2007; 53: 329-336.

Scheckel KG, Chaney RL, Basta NT, Ryan JA. Advances in assessing bioavailability of metal(loid)s in contaminated soils. Advances in agronomy, volume 104. 104, 2009, pp. 1-52.

Schroder JL, Basta NT, Casteel SW, Evans TJ, Payton ME, Si J. Validation of the in vitro gastrointestinal (ivg) method to estimate relative bioavailable lead in contaminated soils. J Environ Qual 2004; 33: 513-521.

Schroder JL, Basta NT, Si JT, Casteel SW, Evans T, Payton M. In vitro gastrointestinal method to estimate relative bioavailable cadmium in contaminated soil. Environ Sci Technol 2003; 37: 1365-1370.

Smith BA, Kirk JL, Stephenson GL. The influence of liquid to soil ratios on arsenic and lead bioaccessibility in reference and field soil. Hum Ecol Risk Assess; 16: 149162.

Smith E, Weber J, Juhasz AL. Arsenic distribution and bioaccessibility across particle fractions in historically contaminated soils. Environ Geochem Health 2009; 31: 85-92.

Snedecor GW, Cochran WG. Statistical methods.: Iowa State University Press, 1980.

Stanek EJ, Calabrese EJ, Barnes RM, Danku JMC, Zhou Y, Kostecki PT, et al. Bioavailability of arsenic in soil: Pilot study results and design considerations. Human \& Experimental Toxicology 2010; 29: 945-960.

Subacz JL, Barnett MO, Jardine PM, Stewart MA. Decreasing arsenic bioaccessibility/bioavailability in soils with iron amendments. J Environ Sci Health, Part A 2007; 42: 1317 - 1329.

Tang X-Y, Zhu Y-G, Shan X-Q, McLaren R, Duan J. The ageing effect on the bioaccessibility and fractionation of arsenic in soils from china. Chemosphere 2007; 66: 1183-1190.

Tang XY, Cui YS, Duan J, Tang L. Pilot study of temporal variations in lead bioaccessibility and chemical fractionation in some chinese soils. Journal of Hazardous Materials 2008; 160: 29-36.

Tang XY, Zhu YG, Cui YS, Duan J, Tang L. The effect of ageing on the bioaccessibility and fractionation of cadmium in some typical soils of china. Environ Int 2006; 32: 682-689.

Theil H. A rank-invariant method of linear and polynomial regression analysis. Indagationes Mathematicae 1950; 12: 85-91. 
Turner A, Ip KH. Bioaccessibility of metals in dust from the indoor environment: Application of a physiologically based extraction test. Environ Sci Technol 2007; 41: 7851-7856.

Van de Wiele TR, Oomen AG, Wragg J, Cave M, Minekus M, Hack A, et al. Comparison of five in vitro digestion models to in vivo experimental results: Lead bioaccessibility in the human gastrointestinal tract. J Environ Sci Health, Part A 2007; 42: 1203 - 1211.

Versantvoort CHM, Van de Kamp E, Rompelberg CJM. Development and applicability of an in vitro digestion model in assessing the bioaccessibility of contaminants from food. 46. RIVM, Bilthoven, 2004.

Waisberg M, Black WD, Waisberg CM, Hale B. The effect of $\mathrm{pH}$, time and dietary source of cadmium on the bioaccessibility and adsorption of cadmium to/from lettuce (lactuca sativa 1. Cv. Ostinata). Food And Chemical Toxicology 2004; 42: 835-842.

Watts MJ, Button M, Brewer TS, Jenkin GRT, Harrington CF. Quantitative arsenic speciation in two species of earthworms from a former mine site. Journal of Environmental Monitoring 2008; 10: 753 -759.

Wragg J. A study of the relationship between arsenic bioaccessibility and its solid phase distribution in wellingborough soils. Geography. Nottingham, Nottingham, 2005.

Wragg J. Bgs guidance material 102, ironstone soil, certificate of analysis. British Geological Survey 2009.

Wragg J, Cave M, Nathanail P. A study of the relationship between arsenic bioaccessibility and its solid-phase distribution in soils from wellingborough, uk. J Environ Sci Health, Part A 2007; 42: 1303 - 1315.

Wragg J, Cave M, Taylor H, Basta N, Brandon E, Casteel S, et al. Interlaboratory trial of a unified bioaccessibility procedure. Open. British Geological Survey, Nottingham, 2009.

Wragg J, Cave MR. In-vitro methods for the measurement of the oral bioaccessibility of selected metals and metalloids in soils: A critical review. Environment Agency, 2003.

Wragg J, Klinck B. The bioaccessibility of lead from welsh mine waste using a respiratory uptake test. J Environ Sci Health, Part A 2007; 42: 1223 - 1231.

Yang JK, Barnett MO, Jardine PM, Brooks SC. Factors controlling the bioaccessibility of arsenic(v) and lead(ii) in soil. Soil Sediment Contam 2003; 12: 165-179.

Zhang H, Huang G-h, Zeng G-m. Health risks from arsenic-contaminated soil in Flin Flon-Creighton, Canada:Integrating geostatistical simulation and dose-response model. Environ Pollut 2009; 157: 2413-2420. 
Table 1 Summary of materials under investigation with published total and relative bioavailable concentrations. Where relative bioavailability is the bioavailable fraction of the contaminant in the soil relative to the bioavailability of a soluble salt of the contaminant.

\begin{tabular}{|c|c|c|c|c|c|c|c|}
\hline Soil & $\begin{array}{l}\text { Total As } \\
\mathrm{mg} \mathrm{kg}^{-1}\end{array}$ & $\begin{array}{c}\text { RBA As } \\
\%\end{array}$ & $\begin{array}{l}\text { Total Cd } \\
\mathrm{mg} \mathrm{kg}^{-1}\end{array}$ & $\begin{array}{l}\text { RBA Cd } \\
\%\end{array}$ & $\begin{array}{c}\text { Total } \\
\mathrm{Pb} \\
\mathrm{mg} \mathrm{kg}^{-1} \\
\end{array}$ & $\begin{array}{l}\mathrm{RBA} \\
\mathrm{Pb} \\
\%\end{array}$ & Material Type \\
\hline As 1 & 11300 & 8.62 & $\mathrm{n} / \mathrm{a}$ & $\mathrm{n} / \mathrm{a}$ & $\mathrm{n} / \mathrm{a}$ & $\mathrm{n} / \mathrm{a}$ & $\begin{array}{l}\text { Calcine Soils(Rodriguez et al., 1999; Basta } \\
\text { et al., 2007) }\end{array}$ \\
\hline As 2 & 17500 & 4.07 & $\mathrm{n} / \mathrm{a}$ & $\mathrm{n} / \mathrm{a}$ & $\mathrm{n} / \mathrm{a}$ & $\mathrm{n} / \mathrm{a}$ & As above \\
\hline As 3 & 13500 & 7.88 & $\mathrm{n} / \mathrm{a}$ & $\mathrm{n} / \mathrm{a}$ & $\mathrm{n} / \mathrm{a}$ & $\mathrm{n} / \mathrm{a}$ & As above \\
\hline As 4 & 11500 & 22.8 & $\mathrm{n} / \mathrm{a}$ & $\mathrm{n} / \mathrm{a}$ & $\mathrm{n} / \mathrm{a}$ & $\mathrm{n} / \mathrm{a}$ & As above \\
\hline As 6 & 405 & 38.7 & $\mathrm{n} / \mathrm{a}$ & $\mathrm{n} / \mathrm{a}$ & $\mathrm{n} / \mathrm{a}$ & $\mathrm{n} / \mathrm{a}$ & $\begin{array}{l}\text { Iron Slag Soils (Rodriguez et al., 1999; } \\
\text { Basta et al., 2007)) }\end{array}$ \\
\hline As 7 & 450 & 43 & $\mathrm{n} / \mathrm{a}$ & $\mathrm{n} / \mathrm{a}$ & $\mathrm{n} / \mathrm{a}$ & $\mathrm{n} / \mathrm{a}$ & As above \\
\hline As 8 & 1180 & 39.1 & $\mathrm{n} / \mathrm{a}$ & $\mathrm{n} / \mathrm{a}$ & $\mathrm{n} / \mathrm{a}$ & $\mathrm{n} / \mathrm{a}$ & As above \\
\hline As 9 & 5020 & 32.9 & $\mathrm{n} / \mathrm{a}$ & $\mathrm{n} / \mathrm{a}$ & $\mathrm{n} / \mathrm{a}$ & $\mathrm{n} / \mathrm{a}$ & As above \\
\hline As 10 & 4650 & 21.9 & $\mathrm{n} / \mathrm{a}$ & $\mathrm{n} / \mathrm{a}$ & $\mathrm{n} / \mathrm{a}$ & $\mathrm{n} / \mathrm{a}$ & As above \\
\hline AR 1 & 676 & 37 & $\mathrm{n} / \mathrm{a}$ & $\mathrm{n} / \mathrm{a}$ & $\mathrm{n} / \mathrm{a}$ & $\mathrm{n} / \mathrm{a}$ & Aberjona River Sediments \\
\hline AR 2 & 313 & 51 & $\mathrm{n} / \mathrm{a}$ & $\mathrm{n} / \mathrm{a}$ & $\mathrm{n} / \mathrm{a}$ & $\mathrm{n} / \mathrm{a}$ & As above \\
\hline ETM 1 & $\mathrm{n} / \mathrm{a}$ & $\mathrm{n} / \mathrm{a}$ & 4109 & 60 & $\mathrm{n} / \mathrm{a}$ & $\mathrm{n} / \mathrm{a}$ & Pt. Mugu Soil 1B \\
\hline ETM 2 & $\mathrm{n} / \mathrm{a}$ & $\mathrm{n} / \mathrm{a}$ & 452 & 89 & $\mathrm{n} / \mathrm{a}$ & $\mathrm{n} / \mathrm{a}$ & CO-SCS Soil \\
\hline ETM 3 & $\mathrm{n} / \mathrm{a}$ & $\mathrm{n} / \mathrm{a}$ & 102 & 79 & $\mathrm{n} / \mathrm{a}$ & $\mathrm{n} / \mathrm{a}$ & OK-SS Soil \\
\hline ETM 4 & $\mathrm{n} / \mathrm{a}$ & $\mathrm{n} / \mathrm{a}$ & 46.8 & 18 & $\mathrm{n} / \mathrm{a}$ & $\mathrm{n} / \mathrm{a}$ & Dugway Soil \#4 \\
\hline NB Cd1 & $\mathrm{n} / \mathrm{a}$ & $\mathrm{n} / \mathrm{a}$ & 465 & 55.4 & $\mathrm{n} / \mathrm{a}$ & $\mathrm{n} / \mathrm{a}$ & $\begin{array}{l}\text { Nick Basta Cd Study sample 1, Blackwell } \\
\text { Soil (Schroder et al., 2003; 2007) }\end{array}$ \\
\hline NBR-255B-04 & $\mathrm{n} / \mathrm{a}$ & $\mathrm{n} / \mathrm{a}$ & 188 & 53.6 & 4050 & 90 & $\begin{array}{c}\text { Nick Basta Pb-Cd studies samples } 5 \text { and 4, } \\
\text { Jasper Yard soil (Schroder et al., 2003; } \\
\text { 2007) }\end{array}$ \\
\hline NBR-256-04 & $\mathrm{n} / \mathrm{a}$ & $\mathrm{n} / \mathrm{a}$ & 29.9 & 10.4 & 11700 & 40 & $\begin{array}{l}\text { Nick Basta Pb-Cd studies samples } 12 \text { and } \\
\text { 6, Murray Slag (Schroder et al., 2003; } \\
\text { 2007) }\end{array}$ \\
\hline NBR-261-04 & $\mathrm{n} / \mathrm{a}$ & $\mathrm{n} / \mathrm{a}$ & 43 & 29.9 & 8530 & 14 & $\begin{array}{l}\text { Nick Basta Pb-Cd studies samples } 2 \text { and 2, } \\
\text { Butte NPL (Schroder et al., 2003; 2007) }\end{array}$ \\
\hline NBR-267-04 & $\mathrm{n} / \mathrm{a}$ & $\mathrm{n} / \mathrm{a}$ & 23.8 & 56.8 & 3200 & 51 & $\begin{array}{l}\text { Nick Basta Pb-Cd studies samples } 13 \text { and } \\
\text { 7, Murray Soil (Schroder et al., 2003; } \\
\text { 2007) }\end{array}$ \\
\hline NBPb 11 & $\mathrm{n} / \mathrm{a}$ & $\mathrm{n} / \mathrm{a}$ & $\mathrm{n} / \mathrm{a}$ & $\mathrm{n} / \mathrm{a}$ & 8170 & 14 & $\begin{array}{c}\text { Nick Basta Pb study sample 11, Midvale } \\
\text { Slag Soil (2007) }\end{array}$ \\
\hline $\mathrm{NBPb} 9$ & $\mathrm{n} / \mathrm{a}$ & $\mathrm{n} / \mathrm{a}$ & $\mathrm{n} / \mathrm{a}$ & $\mathrm{n} / \mathrm{a}$ & 10600 & 20 & $\begin{array}{c}\text { Nick Basta Pb study sample 9, Leadville } \\
\text { Slag Soil (2007) }\end{array}$ \\
\hline B \& V 1A & $\mathrm{n} / \mathrm{a}$ & $\mathrm{n} / \mathrm{a}$ & $\mathrm{n} / \mathrm{a}$ & $\mathrm{n} / \mathrm{a}$ & 1650 & 102 & Composite Soil \\
\hline B \& V 1B & $\mathrm{n} / \mathrm{a}$ & $\mathrm{n} / \mathrm{a}$ & $\mathrm{n} / \mathrm{a}$ & $\mathrm{n} / \mathrm{a}$ & 1630 & 75 & Composite Soil \\
\hline B \& V 2 TM1 & $\mathrm{n} / \mathrm{a}$ & $\mathrm{n} / \mathrm{a}$ & $\mathrm{n} / \mathrm{a}$ & $\mathrm{n} / \mathrm{a}$ & 2280 & 52 & House Dust \\
\hline B \& V 2 TM2 & $\mathrm{n} / \mathrm{a}$ & $\mathrm{n} / \mathrm{a}$ & $\mathrm{n} / \mathrm{a}$ & $\mathrm{n} / \mathrm{a}$ & 2310 & 97 & Composite Soil \\
\hline DNR5 1 & $\mathrm{n} / \mathrm{a}$ & $\mathrm{n} / \mathrm{a}$ & $\mathrm{n} / \mathrm{a}$ & $\mathrm{n} / \mathrm{a}$ & 2830 & 99 & $0.5 \%$ Phosphate-treated soil \\
\hline DNR5 2 & $\mathrm{n} / \mathrm{a}$ & $\mathrm{n} / \mathrm{a}$ & $\mathrm{n} / \mathrm{a}$ & $\mathrm{n} / \mathrm{a}$ & 4230 & 76 & $1 \%$ Phosphate-treated Soil \\
\hline MSE2 & $\mathrm{n} / \mathrm{a}$ & $\mathrm{n} / \mathrm{a}$ & $\mathrm{n} / \mathrm{a}$ & $\mathrm{n} / \mathrm{a}$ & 2020 & 82 & Soil \\
\hline
\end{tabular}


Table 2 Summary data for mean and standard deviation for the relative bioaccessibilities of As in the test samples using the UBM in vitro method. Where "st" is the stomach compartment and "st+int" is the stomach followed by intestinal compartment

\begin{tabular}{|c|c|c|c|c|c|}
\hline Sample Name & $\begin{array}{c}\text { Number of data } \\
\text { points }\end{array}$ & $\begin{array}{c}\text { Relative } \\
\text { Bioaccessibility } \\
(\%) \\
\end{array}$ & $\begin{array}{c}\text { Standard } \\
\text { deviation }(\%) \\
\end{array}$ & $\begin{array}{l}\text { Soil:solution } \\
\text { ratio }\left(\mathrm{g} \mathrm{ml}^{-1}\right)\end{array}$ & Compartment \\
\hline As 1 & 7 & 1.6 & 0.4 & 0.01 & st \\
\hline As 2 & 7 & 1.2 & 0.3 & 0.01 & st \\
\hline As 3 & 7 & 2.5 & 0.7 & 0.01 & st \\
\hline As 4 & 7 & 5.0 & 1.6 & 0.01 & st \\
\hline As 6 & 7 & 24.3 & 10.0 & 0.01 & st \\
\hline As 7 & 7 & 25.7 & 13.1 & 0.01 & st \\
\hline As 8 & 7 & 27.3 & 20.4 & 0.01 & st \\
\hline As 9 & 6 & 23.8 & 15.6 & 0.01 & st \\
\hline As 10 & 7 & 17.7 & 6.0 & 0.01 & st \\
\hline AR 1 & 2 & 10.7 & 0.7 & 0.01 & st \\
\hline AR 2 & 2 & 25.8 & 11.0 & 0.01 & st \\
\hline As 1 & 7 & 1.8 & 0.3 & 0.01 & st+int \\
\hline As 2 & 7 & 1.3 & 0.3 & 0.01 & st+int \\
\hline As 3 & 7 & 2.6 & 0.6 & 0.01 & st+int \\
\hline As 4 & 7 & 5.1 & 1.3 & 0.01 & st+int \\
\hline As 6 & 7 & 8.3 & 5.4 & 0.01 & st+int \\
\hline As 7 & 7 & 6.6 & 5.4 & 0.01 & st+int \\
\hline As 8 & 7 & 5.3 & 3.7 & 0.01 & st+int \\
\hline As 9 & 6 & 7.7 & 4.8 & 0.01 & st+int \\
\hline As 10 & 7 & 6.3 & 5.0 & 0.01 & st+int \\
\hline AR 1 & 2 & 6.7 & 0.7 & 0.01 & st+int \\
\hline AR 2 & 2 & 19.2 & 7.2 & 0.01 & st+int \\
\hline As 1 & 7 & 1.9 & 0.2 & 0.001 & st \\
\hline As 2 & 7 & 1.4 & 0.1 & 0.001 & st \\
\hline As 3 & 7 & 2.6 & 0.2 & 0.001 & st \\
\hline As 4 & 7 & 5.5 & 0.2 & 0.001 & st \\
\hline As 6 & 7 & 44.3 & 2.5 & 0.001 & st \\
\hline As 7 & 7 & 48.9 & 14.6 & 0.001 & st \\
\hline As 8 & 7 & 40.7 & 2.3 & 0.001 & st \\
\hline As 9 & 6 & 37.1 & 0.8 & 0.001 & st \\
\hline As 10 & 7 & 24.1 & 1.6 & 0.001 & st \\
\hline As 1 & 7 & 2.0 & 0.5 & 0.001 & st+int \\
\hline As 2 & 7 & 1.4 & 0.3 & 0.001 & st+int \\
\hline As 3 & 7 & 2.9 & 0.7 & 0.001 & st+int \\
\hline As 4 & 7 & 5.9 & 1.7 & 0.001 & st+int \\
\hline As 6 & 7 & 58.4 & 8.2 & 0.001 & st+int \\
\hline As 7 & 7 & 48.1 & 4.3 & 0.001 & st+int \\
\hline As 8 & 7 & 33.3 & 5.1 & 0.001 & st+int \\
\hline As 9 & 6 & 31.1 & 2.5 & 0.001 & st+int \\
\hline As 10 & 7 & 22.5 & 0.6 & 0.001 & st+int \\
\hline
\end{tabular}


Table 3 Summary data for mean and standard deviation for the relative bioaccessibilities of $\mathrm{Cd}$ and $\mathrm{Pb}$ in the test samples using the UBM in vitro method (soil: solution ratio of $0.01 \mathrm{~g} \mathrm{ml}^{-1}$ for all samples). Where "st" is the stomach compartment and "st+int" is the stomach followed by intestinal compartment.

\begin{tabular}{|c|c|c|c|c|c|}
\hline Sample Name & Element & $\begin{array}{l}\text { Number } \\
\text { of data } \\
\text { points }\end{array}$ & $\begin{array}{c}\text { Relative } \\
\text { Bioaccessibility } \\
(\%) \\
\end{array}$ & $\begin{array}{c}\text { Standard } \\
\text { Deviation (\%) }\end{array}$ & Compartment \\
\hline ETM 1 & $\mathrm{Cd}$ & 6 & 86.4 & 4.5 & st \\
\hline ETM 2 & $\mathrm{Cd}$ & 6 & 85.6 & 5.7 & st \\
\hline ETM 3 & $\mathrm{Cd}$ & 6 & 83.2 & 4.8 & st \\
\hline ETM 4 & $\mathrm{Cd}$ & 7 & 36.0 & 3.0 & st \\
\hline NB Cd 1 & $\mathrm{Cd}$ & 3 & 67.8 & 4.3 & st \\
\hline NBR-255B-04 & $\mathrm{Cd}$ & 1 & 48.4 & 3.0 & st \\
\hline NBR-256-04 & $\mathrm{Cd}$ & 1 & 45.6 & 2.8 & st \\
\hline NBR-261-04 & $\mathrm{Cd}$ & 1 & 24.2 & 1.5 & st \\
\hline NBR-267-04 & $\mathrm{Cd}$ & 1 & 70.7 & 4.0 & $\mathrm{st}$ \\
\hline ETM 1 & $\mathrm{Cd}$ & 6 & 41.9 & 31.0 & st + int \\
\hline ETM 2 & $\mathrm{Cd}$ & 6 & 75.5 & 19.5 & st + int \\
\hline ETM 3 & $\mathrm{Cd}$ & 6 & 107.2 & 51.3 & st + int \\
\hline ETM 4 & $\mathrm{Cd}$ & 7 & 32.1 & 13.3 & st + int \\
\hline NB Cd 1 & $\mathrm{Cd}$ & 3 & 69.9 & 3.4 & st + int \\
\hline NBR-255B-04 & $\mathrm{Cd}$ & 1 & 53.7 & 24.0 & st+int \\
\hline NBR-256-04 & $\mathrm{Cd}$ & 1 & 49.5 & 22.1 & st+int \\
\hline NBR-261-04 & $\mathrm{Cd}$ & 1 & 17.1 & 7.6 & st + int \\
\hline NBR-267-04 & $\mathrm{Cd}$ & 1 & 55.9 & 22.8 & st + int \\
\hline B \& V 1A & $\mathrm{Pb}$ & 6 & 112.8 & 18.5 & st \\
\hline B \& V 1B & $\mathrm{Pb}$ & 7 & 84.5 & 19.0 & st \\
\hline B \& V 2TM1 & $\mathrm{Pb}$ & 7 & 45.2 & 18.7 & st \\
\hline B \& V 2TM2 & $\mathrm{Pb}$ & 7 & 85.5 & 19.8 & st \\
\hline DNR5-1 & $\mathrm{Pb}$ & 7 & 59.0 & 20.6 & st \\
\hline DNR5-2 & $\mathrm{Pb}$ & 7 & 46.0 & 18.8 & st \\
\hline MSE 2 & $\mathrm{~Pb}$ & 6 & 85.4 & 6.6 & st \\
\hline NB Pb 11 & $\mathrm{~Pb}$ & 1 & 0.6 & 0.1 & st \\
\hline NB Pb 9 & $\mathrm{~Pb}$ & 1 & 0.9 & 0.2 & st \\
\hline NBR-255B-04 & $\mathrm{Pb}$ & 1 & 11.6 & 2.7 & st \\
\hline NBR-256-04 & $\mathrm{Pb}$ & 1 & 6.9 & 1.6 & st \\
\hline NBR-261-04 & $\mathrm{Pb}$ & 1 & 10.3 & 2.4 & st \\
\hline NBR-267-04 & $\mathrm{Pb}$ & 1 & 3.2 & 0.7 & st \\
\hline B \& V 1A & $\mathrm{Pb}$ & 6 & 89.5 & 91.3 & st + int \\
\hline B \& V 1B & $\mathrm{Pb}$ & 7 & 43.4 & 33.3 & st + int \\
\hline B \& V 2TM1 & $\mathrm{Pb}$ & 7 & 20.8 & 7.3 & st + int \\
\hline B \& V 2TM2 & $\mathrm{Pb}$ & 7 & 57.6 & 36.4 & st + int \\
\hline DNR5-1 & $\mathrm{Pb}$ & 7 & 30.1 & 24.9 & st + int \\
\hline DNR5-2 & $\mathrm{Pb}$ & 7 & 15.4 & 14.2 & st+int \\
\hline MSE 2 & $\mathrm{~Pb}$ & 6 & 54.0 & 38.1 & st + int \\
\hline NB Pb 11 & $\mathrm{~Pb}$ & 1 & 1.2 & 1.5 & st+int \\
\hline NB Pb 9 & $\mathrm{~Pb}$ & 1 & 1.2 & 1.6 & st+int \\
\hline NBR-255B-04 & $\mathrm{Pb}$ & 1 & 12.3 & 16.1 & st + int \\
\hline NBR-256-04 & $\mathrm{Pb}$ & 1 & 8.8 & 11.4 & st + int \\
\hline NBR-261-04 & $\mathrm{Pb}$ & 1 & 0.1 & 0.1 & st + int \\
\hline NBR-267-04 & $\mathrm{Pb}$ & 1 & 4.6 & 6.0 & st + int \\
\hline
\end{tabular}


Table 4 Summary data for the bioaccessible fraction of the Quality Control samples from each of the participating laboratories. The mean value is in $\mathrm{m} \mathrm{kg}^{-1}$, the relative standard deviations (RSD) are expressed as \%, "st" is the stomach compartment and "st+int" is the stomach followed by intestinal compartment

\begin{tabular}{|c|c|c|c|c|c|c|}
\hline Measurement & $\begin{array}{c}\text { NIST } \\
2710 \\
\end{array}$ & $\begin{array}{c}\text { NIST } \\
2711 \\
\end{array}$ & $\begin{array}{c}\text { BGS } \\
102 \\
\end{array}$ & Element & Compartment & $\mathrm{S}: \mathrm{L} \mathrm{g} \mathrm{ml}^{-1}$ \\
\hline Overall mean & 323 & 55.1 & 4.52 & As & st & 0.01 \\
\hline Repeatability RSD & 5.53 & 3.23 & 26.7 & As & st & 0.01 \\
\hline Reproducibility RSD & 13.8 & 11.0 & 28.2 & As & st & 0.01 \\
\hline Overall mean & 335 & - & - & As & st & 0.001 \\
\hline Repeatability RSD & 7.80 & - & - & As & st & 0.001 \\
\hline Reproducibility RSD & 9.14 & - & - & As & st & 0.001 \\
\hline Overall mean & 264 & 45.6 & 5.38 & As & st+int & 0.01 \\
\hline Repeatability RSD & 0.63 & 8.55 & 35.7 & As & st+int & 0.01 \\
\hline Reproducibility RSD & 6.89 & 22.0 & 44.5 & As & st+int & 0.01 \\
\hline Overall mean & 316 & - & - & As & st+int & 0.001 \\
\hline Repeatability RSD & 13.3 & - & - & As & st+int & 0.001 \\
\hline Reproducibility RSD & 16.0 & - & - & As & st+int & 0.001 \\
\hline Overall mean & 14.8 & 33.8 & 0.281 & $\mathrm{Cd}$ & st & 0.01 \\
\hline Repeatability RSD & 5.83 & 2.58 & 29.9 & $\mathrm{Cd}$ & st & 0.01 \\
\hline Reproducibility RSD & 7.36 & 9.24 & 60.3 & $\mathrm{Cd}$ & st & 0.01 \\
\hline Overall mean & 7.86 & 16.2 & 0.593 & $\mathrm{Cd}$ & $\mathrm{st}+$ int & 0.01 \\
\hline Repeatability RSD & 21.7 & 7.20 & 46.5 & $\mathrm{Cd}$ & st+int & 0.01 \\
\hline Reproducibility RSD & 23.0 & 29.20 & 89.0 & $\mathrm{Cd}$ & st+int & 0.01 \\
\hline Overall mean & 3785 & 958 & 12.8 & $\mathrm{~Pb}$ & st & 0.01 \\
\hline Repeatability RSD & 5.54 & 2.73 & 13.3 & $\mathrm{~Pb}$ & st & 0.01 \\
\hline Reproducibility RSD & 12.4 & 2.96 & 46.8 & $\mathrm{~Pb}$ & st & 0.01 \\
\hline Overall mean & 1138 & 101 & 3.11 & $\mathrm{~Pb}$ & $\mathrm{st}+\mathrm{int}$ & 0.01 \\
\hline Repeatability RSD & 44.2 & 40.8 & 139 & $\mathrm{~Pb}$ & st+int & 0.01 \\
\hline Reproducibility RSD & 80.0 & 94.6 & 141 & $\mathrm{~Pb}$ & st+int & 0.01 \\
\hline
\end{tabular}


Table 5 Summary of method assessment criteria, grey highlights pass the benchmark criteria

\begin{tabular}{|c|c|c|c|c|c|c|c|}
\hline Element & $\begin{array}{c}\text { Liquid to } \\
\text { solid } \\
\text { ratio } \\
\left(\mathrm{ml} \mathrm{g}^{-1}\right)\end{array}$ & Compartment & $\mathrm{r}^{2}$ & $\mathrm{r}$ & slope & $\begin{array}{c}\text { Median } \\
\text { within } \\
\text { RSD }\end{array}$ & $\begin{array}{c}\text { Median } \\
\text { Between } \\
\text { RSD }\end{array}$ \\
\hline $\mathrm{As}$ & 100 & $\mathrm{st}$ & 0.77 & 0.88 & 0.40 & 5.70 & 29.47 \\
\hline $\mathrm{As}$ & 100 & $\mathrm{st}+\mathrm{int}$ & 0.63 & 0.80 & 0.16 & 6.92 & 25.94 \\
\hline $\mathrm{As}$ & 1000 & $\mathrm{st}$ & 0.91 & 0.95 & 0.89 & 3.83 & 7.43 \\
\hline $\mathrm{As}$ & 1000 & $\mathrm{st}+\mathrm{int}$ & 0.83 & 0.91 & 0.88 & 7.26 & 15.72 \\
\hline $\mathrm{Cd}$ & 100 & $\mathrm{st}$ & 0.69 & 0.83 & 0.63 & 3.90 & 7.00 \\
\hline $\mathrm{Cd}$ & 100 & $\mathrm{st}+\mathrm{int}$ & 0.51 & 0.71 & 0.57 & 9.16 & 35.32 \\
\hline $\mathrm{Pb}$ & 100 & $\mathrm{st}$ & 0.61 & 0.78 & 0.78 & 3.59 & 22.78 \\
\hline $\mathrm{Pb}$ & 100 & $\mathrm{st}+\mathrm{int}$ & 0.57 & 0.76 & 0.38 & 14.62 & 81.39 \\
\hline & & & & & & & \\
\hline $\mathrm{Units}$ & & & & & & & $\%$ \\
\hline $\mathrm{Criteria}$ & & & $\geq 0.6$ & $\geq 0.77$ & $\geq 0.8$ & $\leq 10$ & $\leq 20$ \\
\hline
\end{tabular}




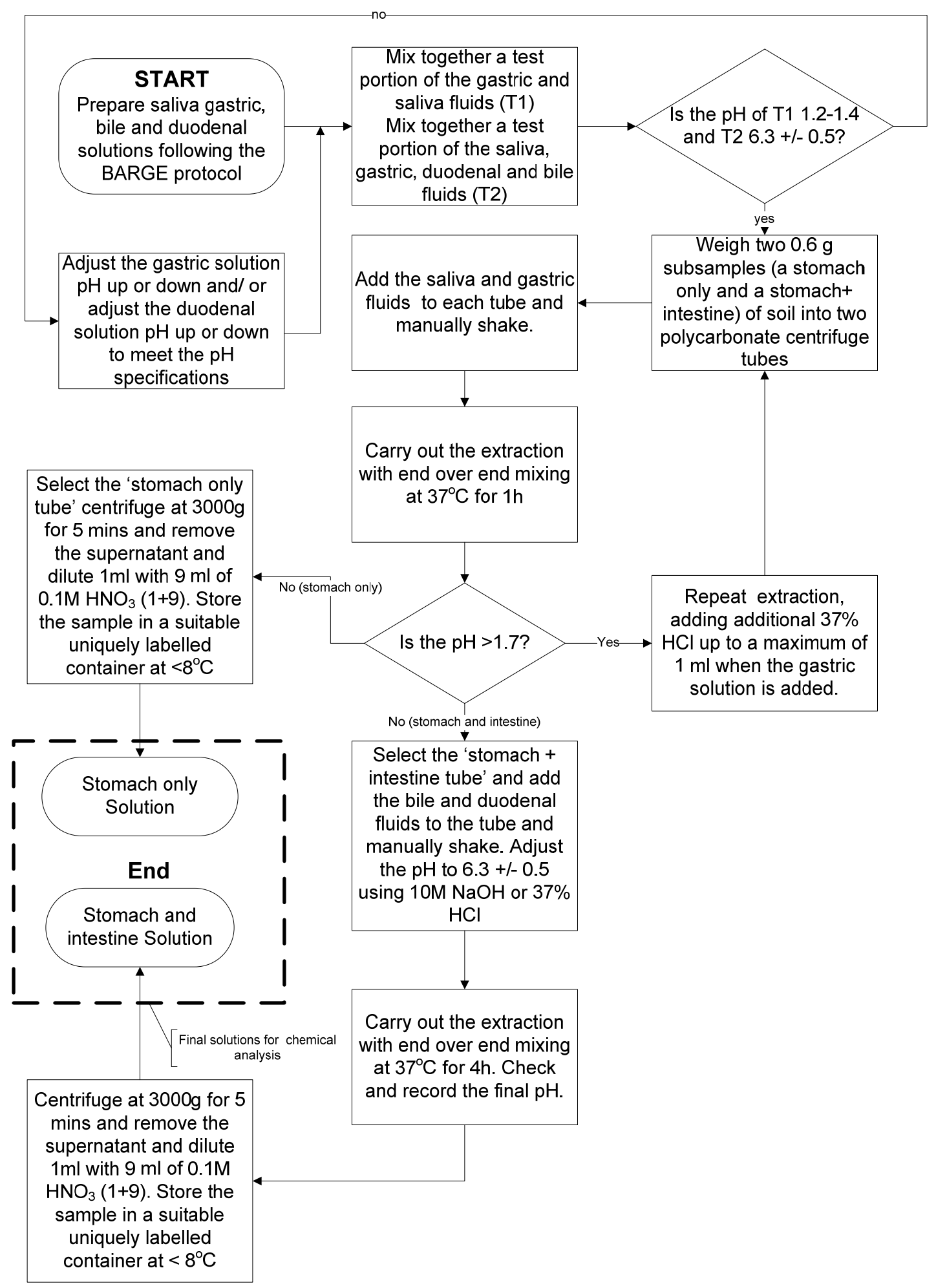

Figure 1-Schematic of the UBM (full details of how the method was used in the interlaboratory study are given in sections 3.2 and 4.4) 


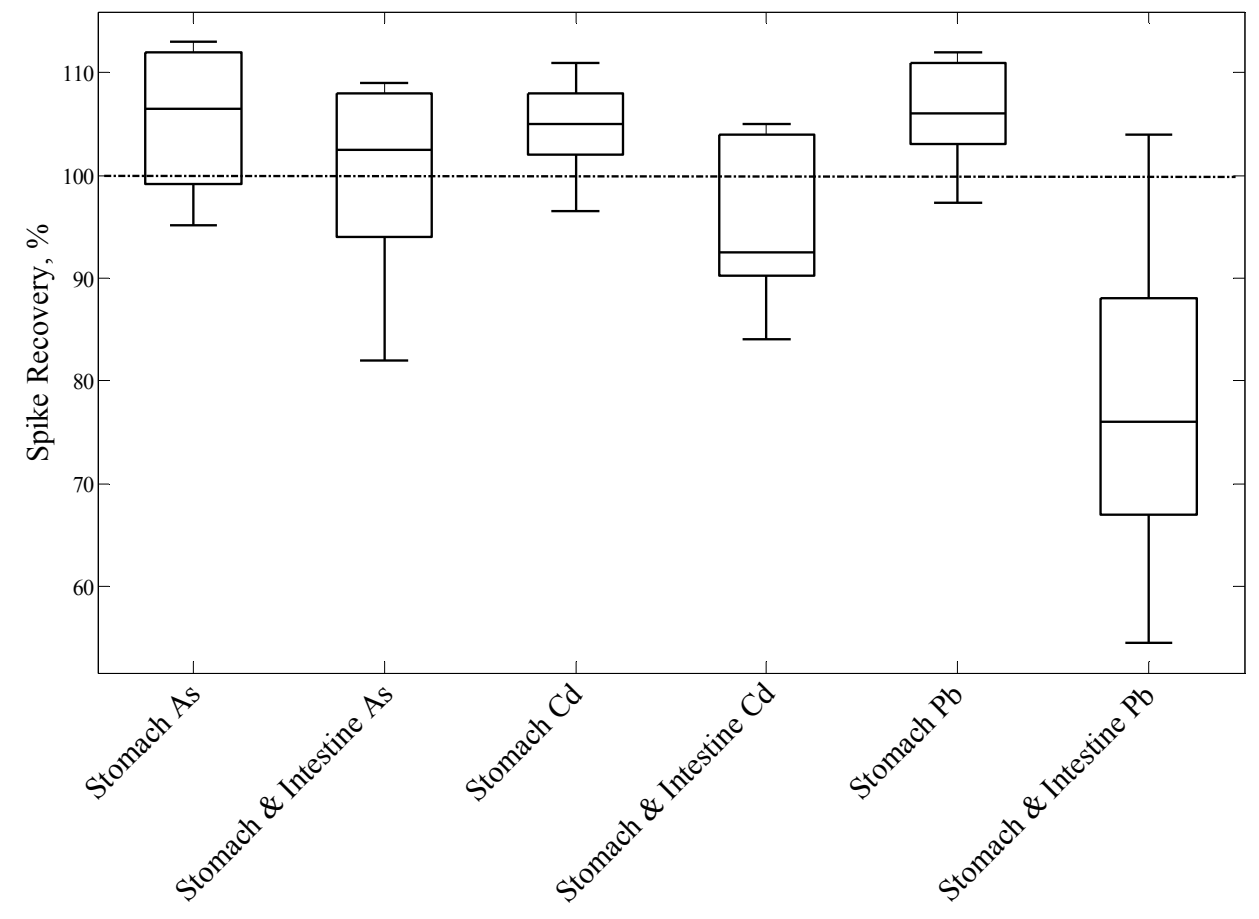

Figure $2 \mathrm{Box}$ and whisker plot summarising the percentage recoveries of $\mathrm{As}, \mathrm{Cd}$ and $\mathrm{Pb}$ in the spiked stomach and stomach \& intestine phase solutions at the standard soil:solution ratio $\left(1: 100 \mathrm{~g} \mathrm{ml}^{-1}\right)$ 


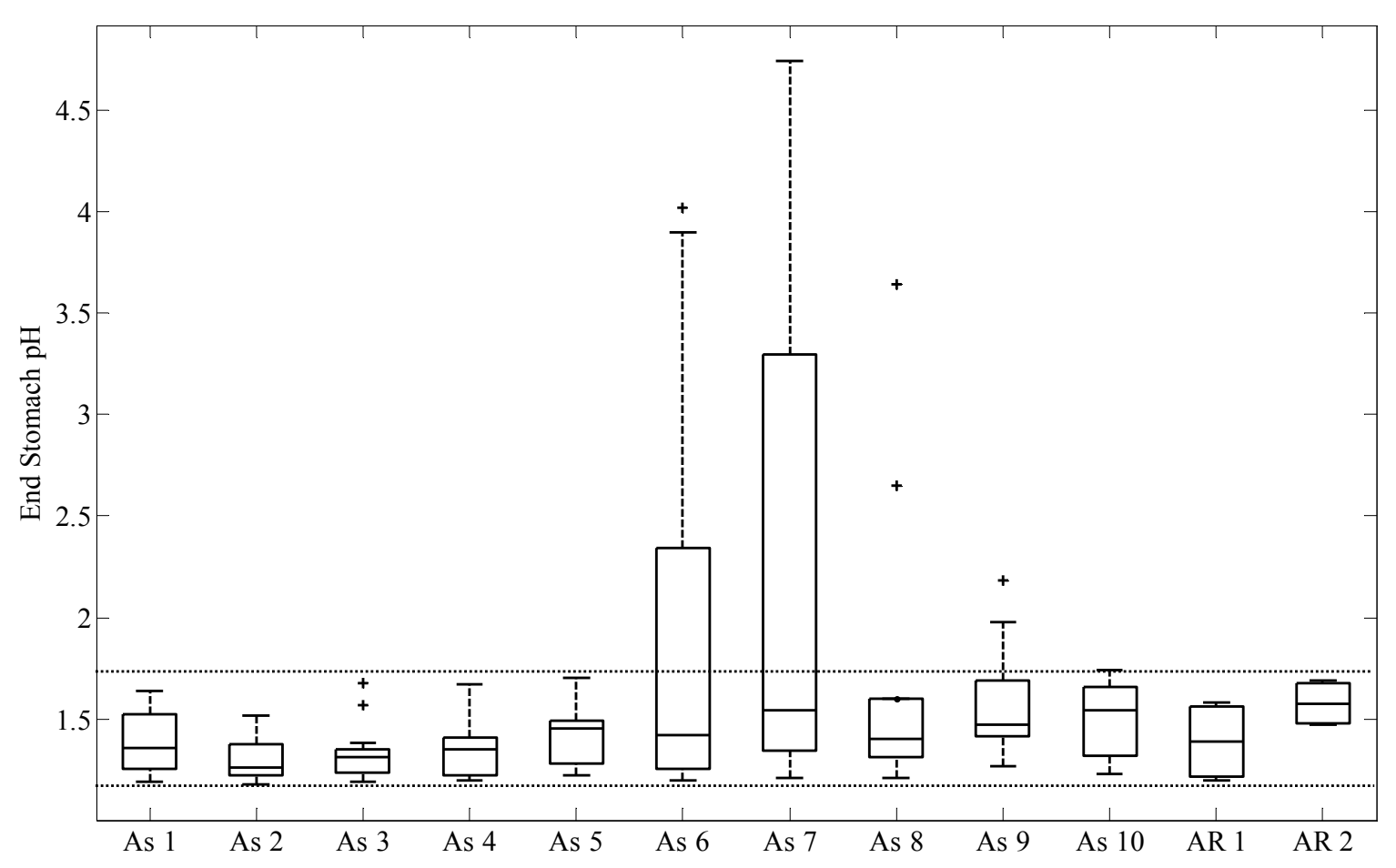

Figure $3 \mathrm{pH}$ tolerance data for the 'stomach' phase of the UBM for the As soils under investigation. The dashed horizontal lines indicate the $\mathrm{pH}$ tolerance at the end of the stomach phase extraction 


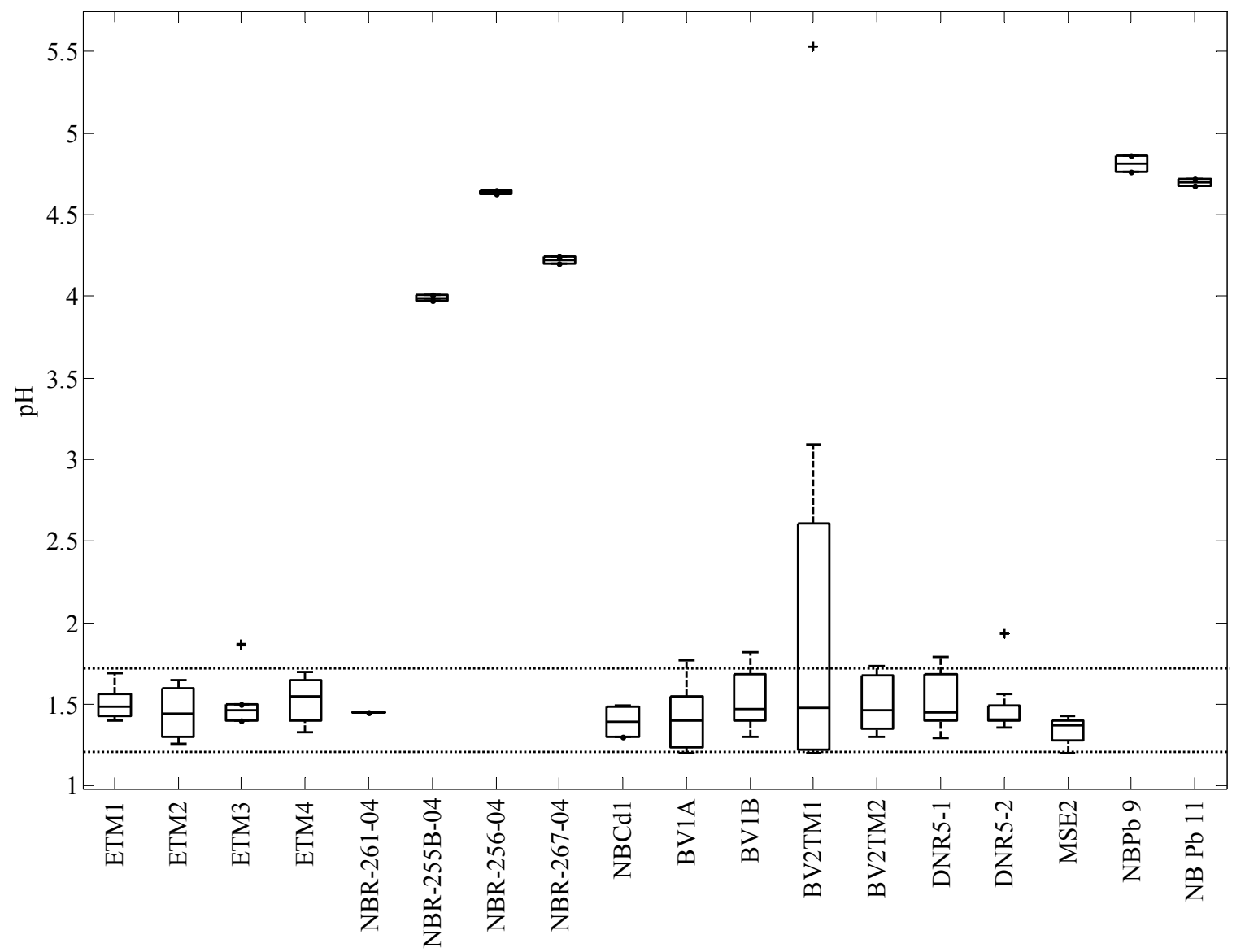

Figure $4 \mathrm{pH}$ tolerance data for the 'stomach' phase of the UBM for the $\mathrm{Cd}$ and $\mathrm{Pb}$ soils under investigation. The dashed lines indicate the $\mathrm{pH}$ tolerance at the end of the stomach phase extraction. 
(a) As Stomach 1:100

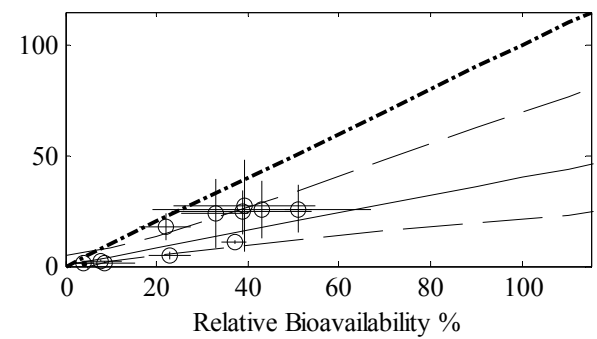

(c) As stomach 1:1000

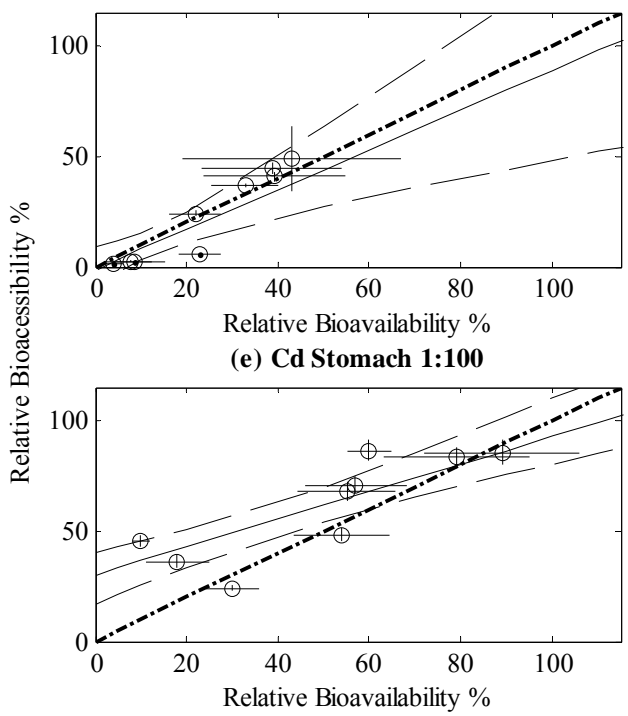

(g) Pb Stomach 1:100

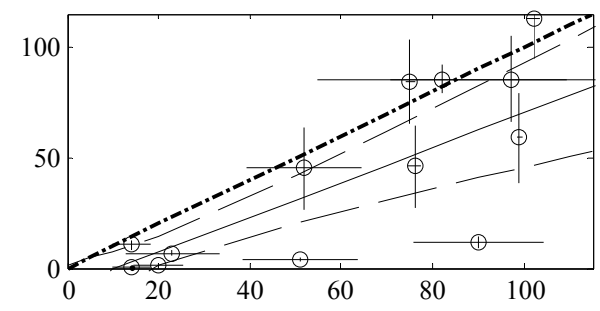

(b) As Stomach+Intestine 1:100

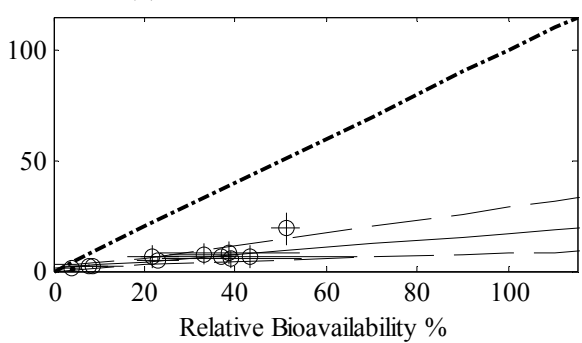

(d) As Stomach+Intestine 1:1000

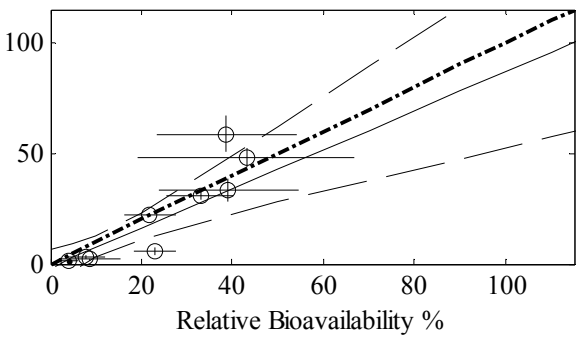

(f) Cd Stomach+Intestine 1:100

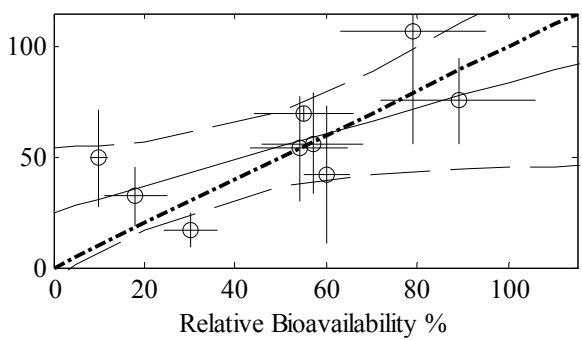

(h) Pb Stomach+Intestine 1:100

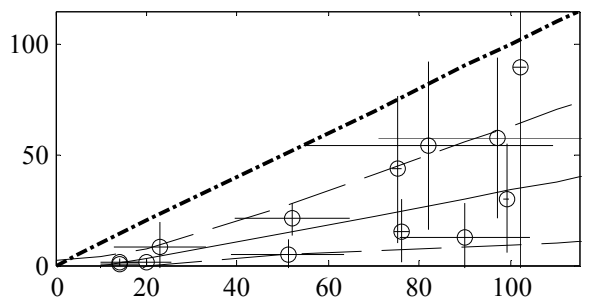

Figure 5 Relative bioaccessibility vs in vivo relative bioavailability for $\mathrm{As} \mathrm{Cd}$ and $\mathrm{Pb}$ in the stomach and stomach and intestine compartments and associated soil:solution ratios. The solid black line shows the median straight line fit, the dotted line shows the line of equivalence and the dashed lines represent the $90 \%$ confidence region. 
(a) As stomach 1:100

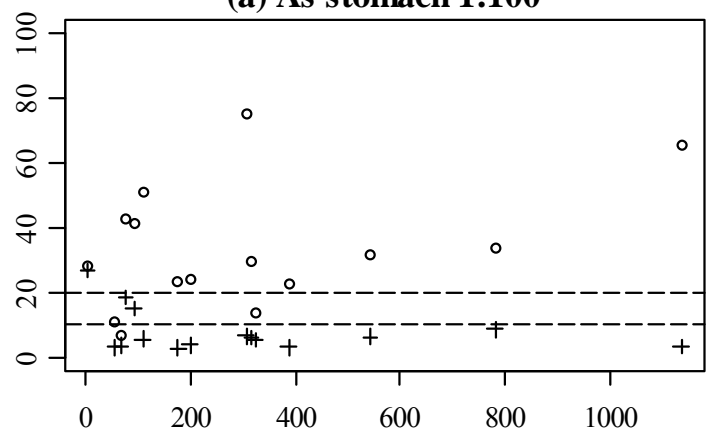

(c) As stomach 1:1000

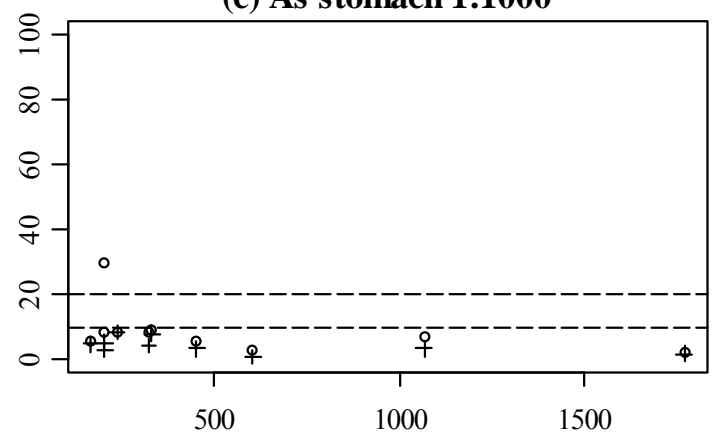

(e) Cd stomach 1:100

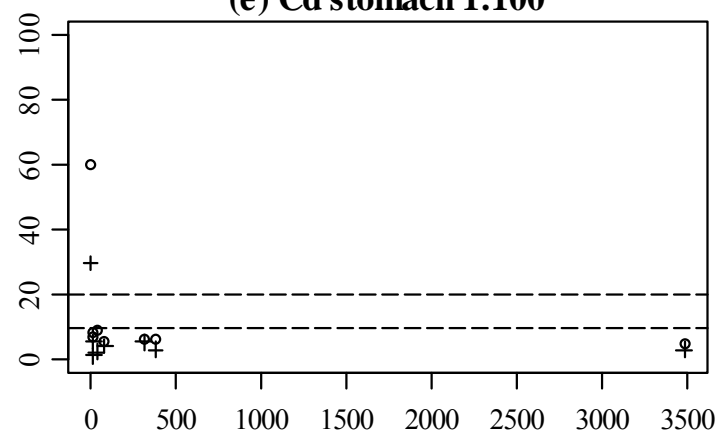

(g) Pb stomach 1:100

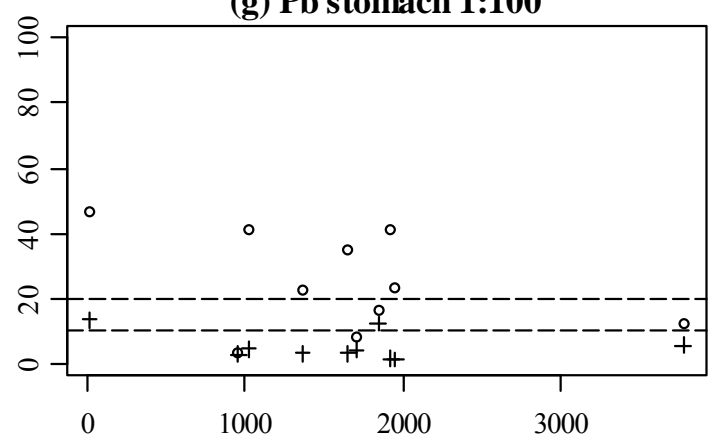

(b) As stomach \& intestine 1:100

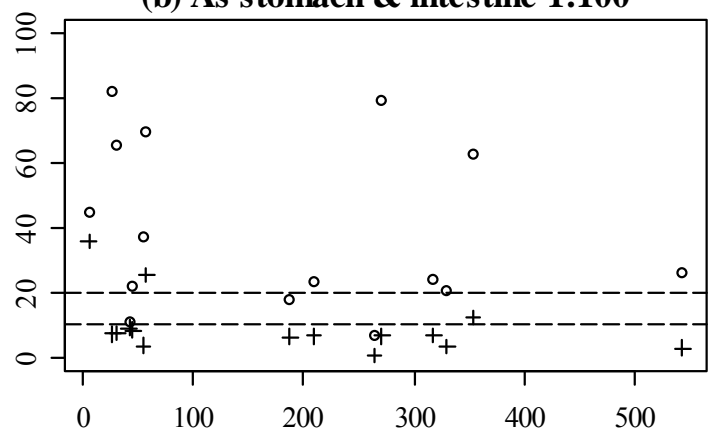

(d) As stomach \& intestine 1:1000

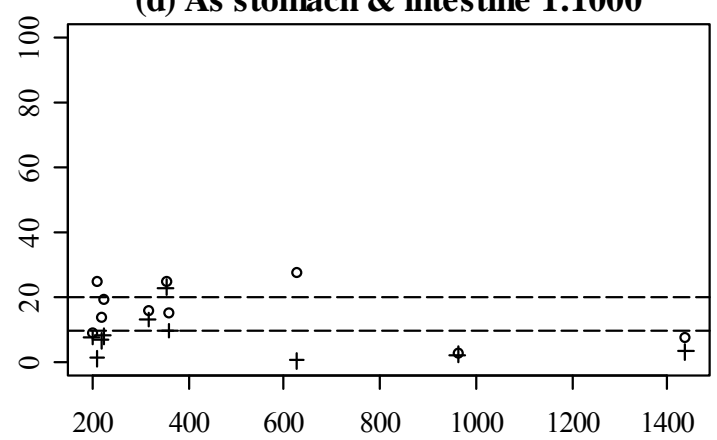

(f) Cd stomach \& intestine 1:100

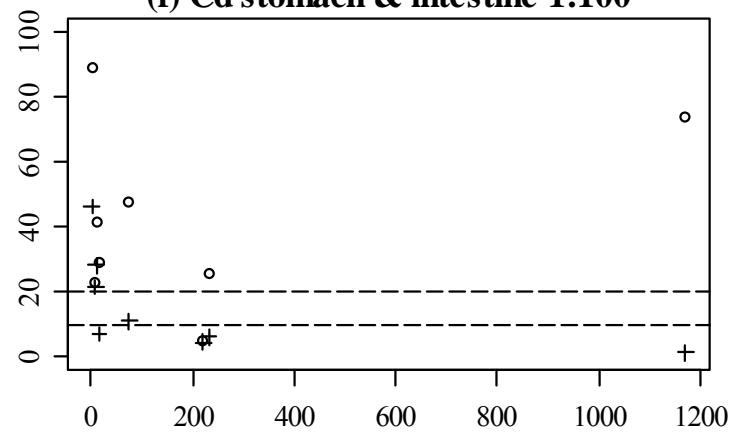

(h) Pb stomach \& intestine 1:100

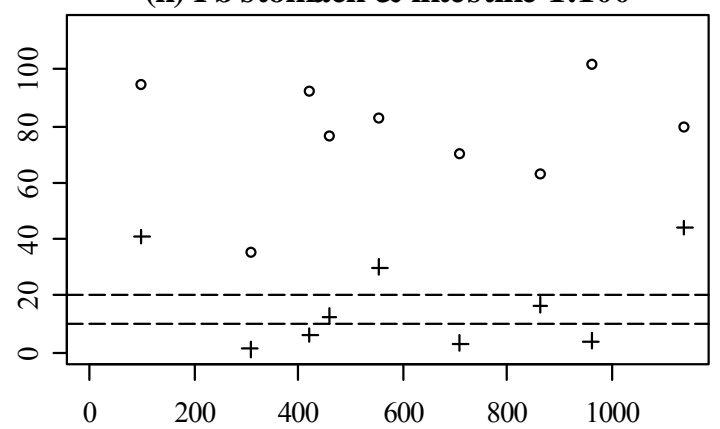

Figure 6 Summary plots of the relative standard deviation (RSD) for $\mathrm{As}, \mathrm{Cd}$ and $\mathrm{Pb}$ for the between-laboratory $(\mathrm{o})$ and within-laboratory $(+)$ bioaccessibility measurements in the stomach and intestine compartments at associated soil:solution ratios. The $\mathrm{x}$-axis represents the bioaccessible value in $\mathrm{mg} \mathrm{kg}^{-1}$ and the $\mathrm{y}$ axis represents the RSD as a percentage. Dashed horizontal lines show 10\% and 20\% RSD. 


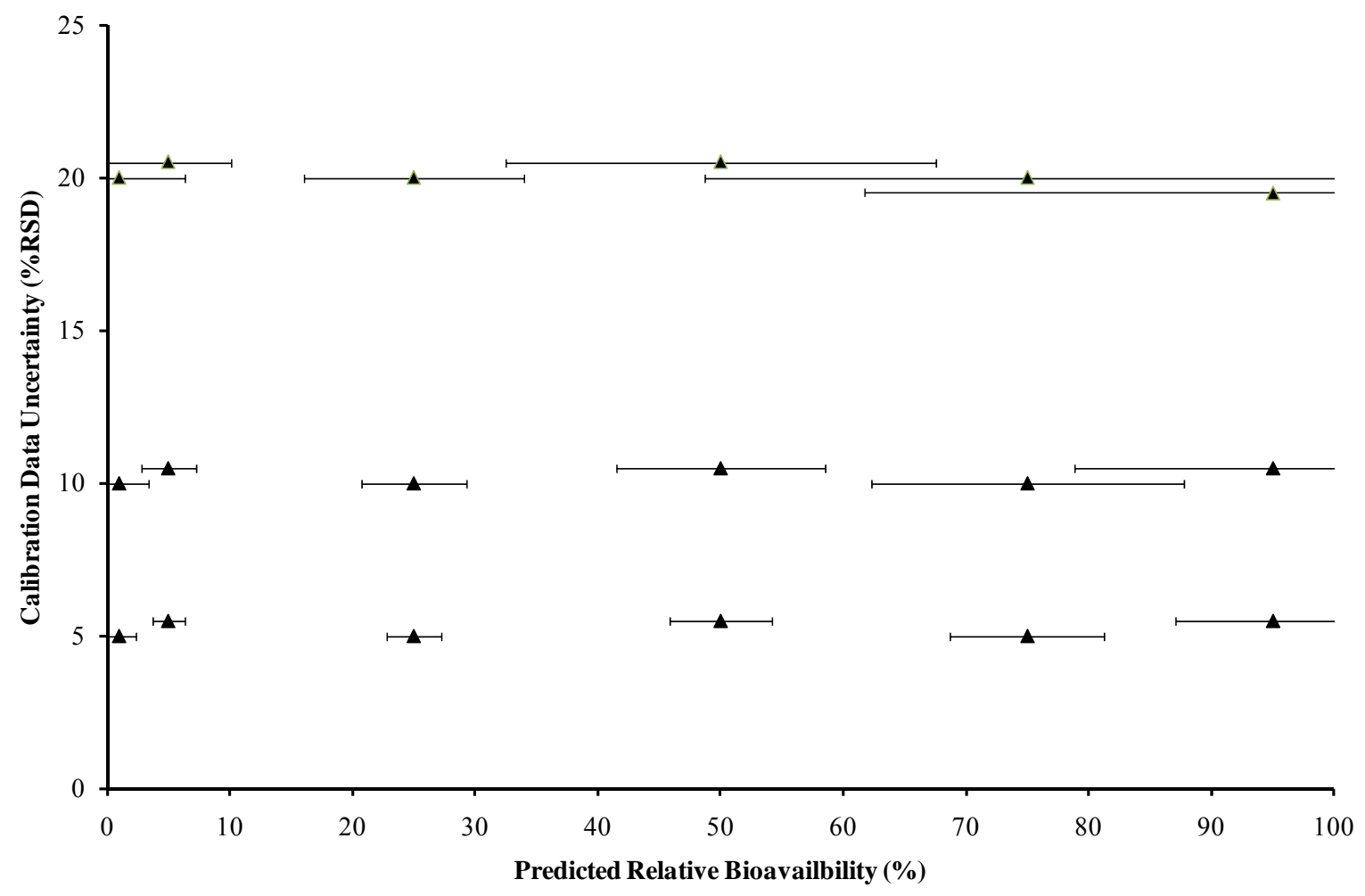

Figure 7 Effect of increasing uncertainty in the bioaccessibility and bioavailability calibration data on the predicted bioavailability. Y axis data have had small shift introduced to so that overlap of error bars can be clearly viewed. 